\title{
特提斯构造域东南端思茅盆地预野井组地层 年代学及其地质意义
}

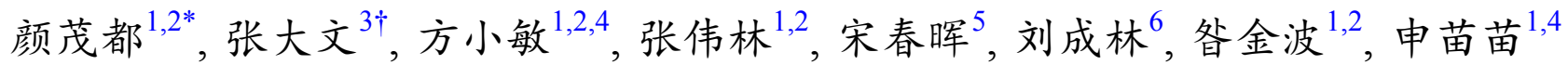

1. 中国科学院青藏高原研究所, 中国科学院大陆碰撞与高原隆升重点实验室, 北京 100101;

2. 中国科学院青藏高原地球科学卓越创新中心, 北京 100101 ;

3. 本庄学院旅游与资源环境学院, 東庄 277160 ;

4. 中国科学院大学, 北京 100049 ;

5. 兰州大学地质科学与矿产资源学院, 甘肃省西部矿产资源重点实验室, 兰州 730000;

6. 中国地质科学院矿产资源研究所成矿作用与资源评价重点实验室, 北京 100037

* 通讯作者, E-mail: maoduyan@itpcas.ac.cn

†通讯作者, E-mail: zhangdawen@uzz.edu.cn

收稿日期: 2020-07-19; 收修改稿日期: 2020-10-18; 接受日期: 2020-10-22; 网络版发表日期: 2021-01-19

国家重点基础研究计划项目(编号：2011CB403000、2017YFC0602803)、中国科学院战略性先导科技专项项目(编号：XDA20070201)、第二 次青藏大科考基金项目(编号：2019QZKK0707)、国家自然科学基金项目(批准号：41988101-01、41907263、41974080)和柊庄学院“青檀学 者”人才项目资助

摘要含钾盐地层年代学认识不清楚, 是造成特提斯构造域东南端大型钾盐矿成矿模式和机制存在争议的主要 原因之一. 为此, 文章针对云南思茅盆地南部江城剖面含钾盐地层敌野井组开展了详细的磁性地层和碎屑锆石U$\mathrm{Pb}$ 年代学研究. 剖面总厚度 $932 \mathrm{~m}$, 共采集了948个古地磁定向岩心和 4 件碎屑锆石 U-Pb年代学样品. 利用系统热退 磁法分离出了857个有效特征剩磁方向，倒转检验、褶皱检验和岩相学分析表明其可能为原生剩磁方向. 这些特 征剩磁方向揭示出剖面含有七个正极性带(N1-N7)和七个负极性带(R1-R7), 可与国际标准极性柱(GPTS2012)的 极性期 C27r C 34n 对比, 揭示笻野井组地层的沉积年代序列为 $>112$ 至 63Ma, 不同于传统认为的预野井组等同于 呵叻含钾盐地层的中下部. 对比分析显示, 思茅盆地与邻区呵叻盆地含钾盐地层年代仅部分重叠, 前者至少要比 后者早开始沉积 $20 \mathrm{Ma}$ ，不同于传统认为的䂛野井组等同于呵叻含钾盐地层的中下部。结合古地理和古气候环境 分析, 思茅与呵叻盆地在白严纪可能属于统一泛盆地. 因此, $85 \mathrm{Ma}^{\mathrm{M}}$ 呵叻盆地大型钾盐矿沉积的时段也可能是思 茅盆地另一个重要的潜在成钾时段.

关键词思茅盆地, 磁性地层学, 含钾盐地层, 吘野井组, $>112 \sim 63 \mathrm{Ma}$, 钾盐成矿

\section{1 引言}

特提斯构造域呈狭长延伸状(图1a), 经由古、
中、新特提斯洋的张开、扩展和闭合演化而成(如 Gehrels等, 2011; Metcalfe, 2013; Yan等, 2016), 是诸多 矿产资源的聚集地(如郑绵平等，2006; Hou等，2007; 


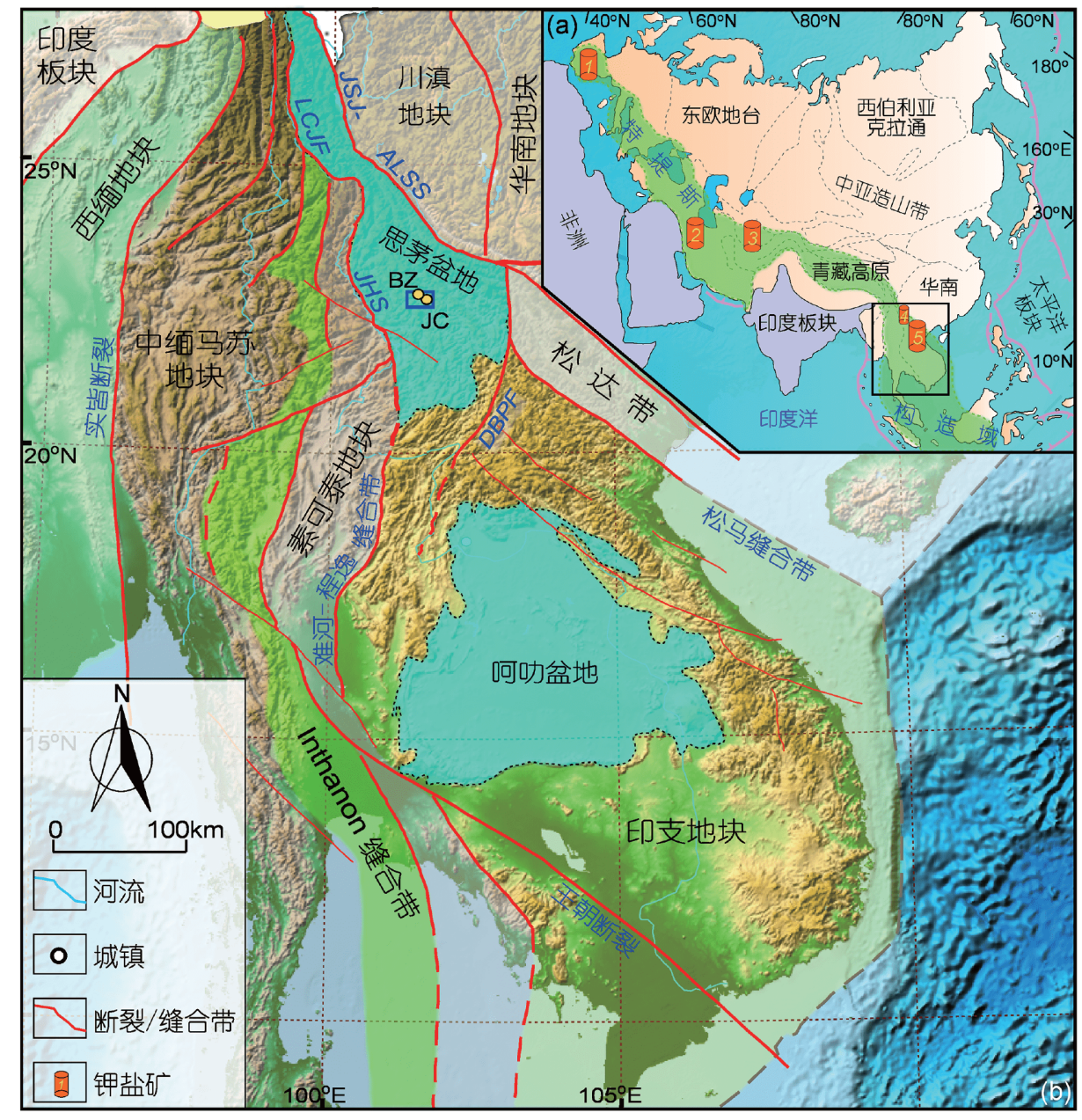

图 1 研究区周边构造单元及钾盐矿分布

(a) 特提斯域代表性钾盐矿分布图. 1, 埃布罗盆地; 2, 大卡维尔盆地; 3, 中亚盆地; 4, 思茅盆地; 5, 呵叻盆地. (b) 研究区构造单元. 修改自 Metcalfe (2013). JHS, 景洪缝合带; JSJ-ALSS, 金沙江-哀牢山缝合带; LCJF, 澜沧江断裂; DBPF, 奠边府断裂(Dien Bian Phu fault). 蓝色矩形框为 研究区位置, 框内两个城镇分别为宝藏乡(BZ)和江城(JC)

Wang等, 2011; Fu等, 2013; 邓军等, 2020). 从该带西部 的西班牙到东部的东南亚内发育了众多大型钾盐矿床 (Warren, 2010; 刘成林等, 2015), 如埃布罗盆地、大卡 维尔盆地、中亚盆地、思茅盆地和呵叻盆地等(图1a). 开展这些盆地内钾盐成矿研究将有助于理解特提斯构 造域内/外类似蒸发岩盆地的成矿过程.

呵叻盆地和思茅盆地位于特提斯域东南端(图1b). 其中, 呵叻盆地马哈萨拉堪组(MSF)地层蕴藏有世界 上最大的钾盐矿床之一, $\mathrm{K}_{2} \mathrm{O}$ 远景储量超过 266 亿吨 (Fan，2000)，而思茅盆地㐨野井组地层中已探明钾盐 储量仅 0.17 亿吨. 预野井钾盐矿是目前中国大陆唯一 的前第四纪固体钾盐矿床，具有良好的钾盐勘探潜力
(曲懿华等, 1998; 郑绵平等, 2014). 一些研究表明, 预 野井组与马哈萨拉堪组具有一致的蒸发岩沉积层序, 两个盆地的钾盐矿具有相似的矿物成分、沉积环境和 物质来源，因而具有密切的联系(曲懿华等，1998). 尽 管已开展了大量研究，但是对于这两个盆地钾盐矿的 形成机制仍然存在争议，如海源(Hite和Japakasetr, 1979; 曲懿华，1997; El Tabakh等，1999; Wang等, 2014; Li M等, 2018; Qin等, 2020)、陆源(张嘉澎和李 官贤, 1980; Li等, 2015)、热液补给(El Tabakh等, 1999; 张西营等, 2015; Li M等, 2018)或多源(Qin等, 2020)等. 同时, 与其它诸多钾盐矿床(如下刚果盆地的Mboukoumassi钾盐矿(Zhao等, 2017; Liu等, 2018))类似，两个盆 
地含钾盐地层的年代学认识尚不明确, 尤其是思茅盆 地预野井组地层. 尽管呵叻盆地马哈萨拉堪组地层年 代还存在一定的不确定性, 大家普遍认为其系晚白严 世地层(如钟晓勇等, 2012; 秦占杰等, 2013; Hansen等, 2016; Zhang等, 2018; Qin等, 2020); 而对于预野井组地 层年代的认识, 主要包括: (1) 古新世地层, 主要基于少 量介形类和轮藻化石组合, 是自上世纪九十年代以来 的主流观点(如叶春辉和蒋志文, 1981; 云南省地质矿 产局, 1996; 曲懿华等, 1998; 郑绵平等, 2006); (2) 早白 严世晚期-晚白严世地层, 主要基于有限的介形类化石 (云南省地质矿产局, 1976)、狍粉(如陈乐尧, 1980; 袁 秦等, 2013)和凝灰岩夹层年代(Wang等, 2015); (3) 中 侏罗世地层, 主要是早期基于地层接触关系(云南省地 质矿产局, 1996)推测. 两个盆地含钾盐地层(尤其是预 野井组)年代的不确定性, 是制约两个盆地钾盐矿床关 系、成钾模式和机制认识的主要因素之一.

在东亚地区, 磁性地层学被广泛应用于约束长序 列地层的沉积年代(如黄宝春等，2005; He等，2012; Deng等, 2013; Zhang等, 2019). 比如, 通过开展钻孔 (CCSD-SK-I)沉积层序的高精度磁性地层学研究, He 等(2012)和Deng等(2013)成功建立了中国东北松辽盆 地晚白严世地层的精确年代序列, 等. 本研究旨在通过 磁性地层学和碎屑锆石 $\mathrm{U}-\mathrm{Pb}$ 年代学相结合的方法, 获 得思茅盆地槛野井组地层的准确沉积年代, 并开展与 呵叻盆地含钾盐地层的对比分析. 进而结合区域古地 理和古气候证据, 探讨思茅与呵叻盆地白严纪钾盐矿 的关系.

\section{2 材料和方法}

\section{1 地质背景}

思茅盆地位于印支陆块西北部, 面积约7万平方公 里(图1b). 思茅陆块东北部与华南陆块以金沙江-哀牢 山缝合带为界, 西侧和素可泰陆块以澜沧江-景洪缝合 带相接(Sone和Metcalfe, 2008; Metcalfe, 2011，2013) (图1b), 南部与呵叻盆地通过奠边府断裂分隔, 是一个 在澜沧江洋和金沙江洋消亡后发展起来的中-新生代 陆内盆地(朱创业等, 1997). 盆地内主要沉积中生代至 早新生代陆相红层, 总厚度超过 $8000 \mathrm{~m}$. 仅在盆地西侧 分布有少量不整合于古生代地层之上的晚三叠世火山 岩和早侏罗世海相泥岩、砂岩. 中生代岩石在始新世-
渐新世期间发生禇皱变形, 形成了近北西-南东向的弯 山构造(Wang等, 1998).

含钾盐地层预野井组位于早白严世虎头寺组之 上, 上覆始新世等黑组地层, 被划分为三段(云南省地 质矿产局, 1996; 曲懿华等, 1998). 预野井组下段表现 为一套红色-棕红色泥砾岩、泥岩和砂岩为主的含蒸 发岩(石盐、石膏)层序; 中段主要由棕红色粉砂岩、 泥岩与少量细砂岩、黄色泥岩、泥灰岩夹层组成; 上 段包括两个亚段, 其中下亚段为主要含矿段, 为石 盐、钾盐、石膏夹泥砾岩和粉砂岩等, 上亚段主要为 棕红色粉砂岩、泥岩和细砂岩(曲懿华等, 1998). 预野 井组与呵叻盆地马哈萨拉堪组含蒸发岩地层具有可对 比的层序，后者自下而上包括底部硬石膏层、下盐 层、下碎屑层、中盐层、中碎屑层、上盐层和上碎屑 层(如Hite和Japakasetr, 1979; El Tabakh等, 1999; Zhang 等, 2018), 预野井组缺失其上盐层(曲懿华等, 1998).

思茅盆地钻孔资料揭示含钾盐矿层可能位于预野 井组地层上段(曲懿华等, 1998). 然而, 含钾盐矿层的 具体层位以及是否为地层中的原始沉积 (曲懿华等, 1998; Wang等, 2015)或由深部侏罗纪钾盐受挤压塑流 到预野井组地层中就位(即“二层楼成矿模式”; 郑绵平 等, 2014)仍然存在争议.

\section{2 样品采集}

野外地质调查显示, 思茅盆地南缘位于预野井钾 盐矿以南约 $20 \mathrm{~km}$ 的江城地区发育连续的白严纪-古近 纪地层(图2a), 是开展详细磁性地层学研究的理想场 所. 江城(JC)剖面(图2a, $A-A^{\prime}$ )位于江城县西北, 因道 路开挖出露完整的预野井组地层, 总厚度大约 $932 \mathrm{~m}$. 其中, 预野井组地层上部 $(0 \sim 423 \mathrm{~m})$ 由红色细砂岩和紫 红色粉砂岩、泥岩组成(图2b, 2c); 中部(423 615m) (图 2b，2d) 总体表现为棕红-紫红色泥岩; 下部 (615 932m) 主要为紫红色泥岩, 含泥砾(图2b, 2e). 预 野井组地层底部与曼岗组地层顶部砂岩之间呈整合 接触.

野外采样工作分别在2012、2015和2018年开展. 使用便携式汽油动力钻机(D026-T6型)按照0.5 2m间 隔(仅底部由于出露较差扩大至4 8m) 从预野井组地层 共获得948个古地磁定向岩芯, 及从下伏曼岗组顶部采 集少量古地磁样品. 同时, 在曼岗组地层底部的向斜两 翼采集了 38 个古地磁褶皱检验样品. 此外, 从预野井组 


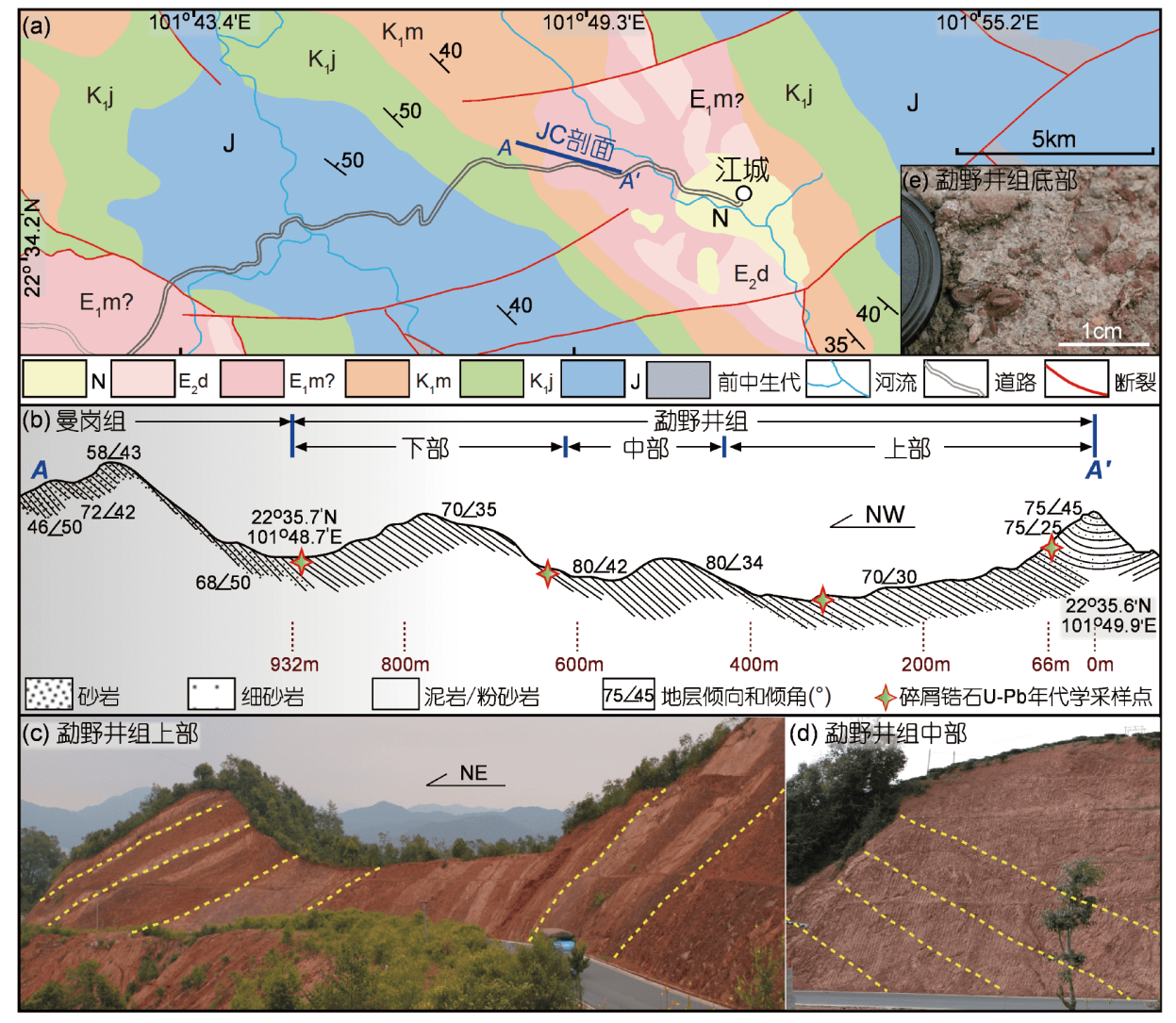

图 2 研究区地质图及野外照片

(a) 江城地区地质图; (b) 江城剖面 $\left(A-A^{\prime}\right)$ 横剖面图; (c) (e) 野外地层照片. $\mathrm{N}$, 新近纪; $\mathrm{E}_{2} \mathrm{~d}$, 始新世等黑组; $\mathrm{E}_{1} \mathrm{~m}$ ?, 古新世(?)预野井组; $\mathrm{K}_{1} \mathrm{~m}$, 早白 严世曼岗组; $K_{1} \mathrm{j}$, 早白严世景星组; $J$, 侏罗纪. 角度单位为 $\left(^{\circ}\right)$

地层不同层位采集了四件用于碎屑锆石 $\mathrm{U}-\mathrm{Pb}$ 年代学 分析的粉砂岩和细砂岩样品(每件 $7 \mathrm{~kg}$ ). 所有古地磁 样品使用太阳罗盘定向，使用GPS确定采样点位置坐 标，及根据第11代国际地磁参考场(Finlay等，2010)计 算得到研究区的现今地磁场偏角 $\left(-1.8^{\circ}\right)$.

\section{3 实验方法}

\subsection{1 岩石磁学分析和岩相学观测}

为了判断预野井组地层的后期扰动作用，按照 1 2m间隔选取古地磁样品在MFK1-FA Kappabridge磁 化率仪(AGICO, 捷克)上进行磁组构测试分析. 为确定 㐨野井组地层中的携磁矿物种类，对不同岩性代表性 样品进行了岩石磁学分析，包括磁化率随温度变化曲 线 $(\chi-T$ 曲线 $) 、$ 磁化强度随温度变化曲线 $(M-T$ 曲线 $) 、$ 三轴等温剩磁(IRM)热退磁曲线、磁滞回线和IRM获 得曲线. 其中, $\chi$ - $T$ 曲线测试方法参照Shen等(2020). $M$ -
$T$ 曲线在居里称(VFTB)上完成, 样品在 $1 \mathrm{~T}$ 外加场中从 $\sim 40^{\circ} \mathrm{C}$ 按照 $40^{\circ} \mathrm{C} \mathrm{min}^{-1}$ 的速率加热至 $700^{\circ} \mathrm{C}$. 对于三轴 IRM热退磁曲线, 首先使用IM-100型脉冲磁化仪(ASC, 美国)在样品的三个正交方向分别施加 $1.7 、 0.4$ 和 0.15T的外加场来获得IRM，随后使用TD-48型热退磁 仪(ASC，美国)以 $10 \sim 40^{\circ} \mathrm{C}$ 稳定间隔将样品逐步加热至 $\sim 690^{\circ} \mathrm{C}$, 最后在Minispin小旋转磁力仪(Molspin, 英国) 上测量加热后的剩磁强度和方向. 磁滞回线的测量在 Micromag 2900交变梯度磁强计(Princeton, 美国)上完 成，外加场范围是 $\pm 0.5 \mathrm{~T}$. 等温剩磁获得曲线及反向场 退磁曲线均使用Micromag VSM3900振动式磁强计 (Princeton，美国)完成，施加最大为 $1 \mathrm{~T}$ 的外加场，随后 在反向场中退磁至1T以获得样品的剩磁矫顽力 (Bcr). 上述实验中磁组构、 $\chi-T$ 曲线和三轴IRM热退磁实验 均在中国科学院青藏高原研究所完成, $M-T$ 曲线在华 东师范大学河口海岸学国家重点实验室完成. 磁滞回 
线在德国图宾根大学地球科学系完成. IRM获得曲线 及反向场退磁曲线在中国地震局地球物理研究所 完成.

此外, 为获得样品中磁性颗粒的矿物学特征, 对代 表性砂岩和紫红色泥岩样品岩石薄片在中国科学院青 藏高原研究所开展了显微镜下观察和电子探针(JXA8230 , JEOL, 日本)分析. 岩石薄片在廊坊宇能岩石矿 物分选技术服务有限公司完成制作. 显微观察使用 Axio Imager. M2m型偏光显微镜(Carl Zeiss AG，德 国)完成. 电子探针分析包括背散射图像(BSE)和能谱 (EDS)分析.

\subsection{2 退磁分析}

为获得特征剩磁方向，使用TD-48型热退磁炉对 所有994个古地磁样品进行了14 20步系统热退磁分 析. 退磁温度区间从 100 至 $700^{\circ} \mathrm{C}$ 或直到天然剩磁 $(\mathrm{NRM})$ 强度在 $5 \%$ 以下, 在 $585^{\circ} \mathrm{C}$ 以下按照 $30 \sim 100^{\circ} \mathrm{C}$ 升 温, 之后加热间隔为 $1 \sim 30^{\circ} \mathrm{C}$. 剩磁采用 $2 \mathrm{G}-755$ 型超导 岩石磁力仪(Rapid系统)测量. 上述实验均在中国科学 院青藏高原研究所磁屏蔽室(平均磁场强度为 $170 \mathrm{nT}$ ) 内完成. 退磁数据使用软件PaleoMag v 3.1d40处理并 通过正交投影图(Zijderveld, 1967)分析. 各个剩磁组分 由主成分分析法(Kirschvink，1980)获得. 古地磁平均 方向通过Fisher统计得到(Fisher, 1953).

\subsection{3 锆石U-Pb年代学}

利用传统重液和磁选方法从每件样品中分选出超 过 2000 个锆石颗粒，并使用双目显微镜经人工挑选出 高纯度锆石样品. 随后每件样品中随机选取 250 颗锆 石用环氧树脂固定，将锆石打磨至原厚度的一半. 对 抛光好的锆石进行反射光、透射光和阴极发光 $(\mathrm{CL})$ 图 像综合观察，确定用于U-Pb分析的目标点位. 锆石颗 粒的提取和挑选、图像拍摄分别在廊坊宇能岩石矿物 分选技术服务有限公司和南京宏创地质勘探技术服务 有限公司完成. 锆石 $\mathrm{U}-\mathrm{Pb}$ 定年测试在中国科学院青藏 高原研究所采用激光剥蚀电感耦合等离子体质谱仪 (LA-ICP-MS) 完成, 激光剥蚀系统为美国New Wave公 司生产的P193FX型193nm ArF准分子系统，电感耦合 等离子体质谱仪(ICP-MS)型号为美国安捷伦科技有限 公司生产的Aglient 7500a型. 每件样品选取120 140颗 锆石进行测试, 详细程序参考Cai等(2012). 采用Isoplot
程序(Ludwig，2003)计算加权平均值年龄和绘制年龄 分布频率图、U-Pb谐和图. 对于谐和度低于 $90 \%$ 的锆 石点舍弃不用,小于 $1000 \mathrm{Ma}$ 锆石采用 ${ }^{206} \mathrm{~Pb} /{ }^{238} \mathrm{U}$ 年龄, 大于 $1000 \mathrm{Ma}$ 锆石采用 ${ }^{207} \mathrm{~Pb} /{ }^{206} \mathrm{~Pb}$ 年龄 (Gehrels等, 2006).

\section{3 结果}

\section{1 岩石磁学结果}

AMS结果显示在地层坐标下, 大多数样品的磁化 率最小轴 $\left(K_{\min }\right)$ 集中分布在圆心附近, 平均磁倾角为 $\sim 86.6^{\circ}$, 而磁化率最大轴 $\left(K_{\max }\right)$ 分布比较分散、呈近北 西-南东走向且磁倾角整体偏低 $\left(<20^{\circ}\right)$ (图3a), 指示了 沉积组构(Tarling和Hrouda, 1993; Parés等, 1999; Parés 和van der Pluijm, 2002). 磁面理(F)和磁线理(L)相关关 系(或弗林图解)显示磁化率椭球体以扁圆状为主(图 $3 b)$, 具有明显的沉积起源特征. 同时磁化率与校正后 的各向异性度 $(\mathrm{P} j)$ 呈显著线性相关关系(图3c), 表明 $\mathrm{P} j$ 受岩性控制(Sun等, 2016). 此外, P j-T(形状因子)图解 显示大多数样品的 $\mathrm{T}>0$, 且 $\mathrm{P}$ j较小 (在1.0005 1.172之间 变化, 平均值为 1.04) (图3d). 因此, 预野井组古地磁样 品记录的很可能是沉积磁组构, 受到构造应力的影响 十分微弱.

$\chi-T$ 和 $M-T$ 曲线显示所有样品的磁化率(图3e 3h) 和磁化强度(图3i 31)在 $\sim 680^{\circ} \mathrm{C}$ 快速降低, 说明样品的 磁性矿物以赤铁矿为主, 来自㐨野井组地层上部样品 的磁化率和磁化强度在 $~ 580^{\circ} \mathrm{C}$ 有降低趋势(图3e，3f, $3 \mathrm{i}, 3 \mathrm{j}$ ), 指示了磁铁矿的存在. 磁化强度在 300 到 $450^{\circ} \mathrm{C}$ 之间的下降可能与磁赤铁矿有关(图3i, 3j). 此外, 代表 性样品磁化率值 $\left(\chi_{0}\right)$ 的变化特征(图3e 3h) 指示预野井 组地层中部和下部的磁性矿物含量高于上部.

三轴IRM热退磁结果显示所有样品的中间和硬磁 组分或者三个磁组分强度均在 $680^{\circ} \mathrm{C}$ 左右解阻(图 $3 \mathrm{o}$, $3 p$ ), 进一步说明赤铁矿是主要的磁性矿物. 预野井组 上部样品的硬磁和软磁组分在 $550 \sim 620^{\circ} \mathrm{C}$ 明显降低(图 $3 \mathrm{~m}, 3 \mathrm{n})$, 也说明该段存在少量的磁铁矿.

所有经过顺磁校正后的磁滞回线在 $500 \mathrm{mT}$ 外加场 中均未闭合(图3q 3t), 指示样品中广泛存在高矫顽力 磁性矿物. 来自预野井组地层上部样品的磁滞回线呈 明显的蜂腰状, 说明同时存在低矫顽力(如磁铁矿)和 高矫顽力(如赤铁矿)磁性成分(Roberts等, 1995; Tauxe 

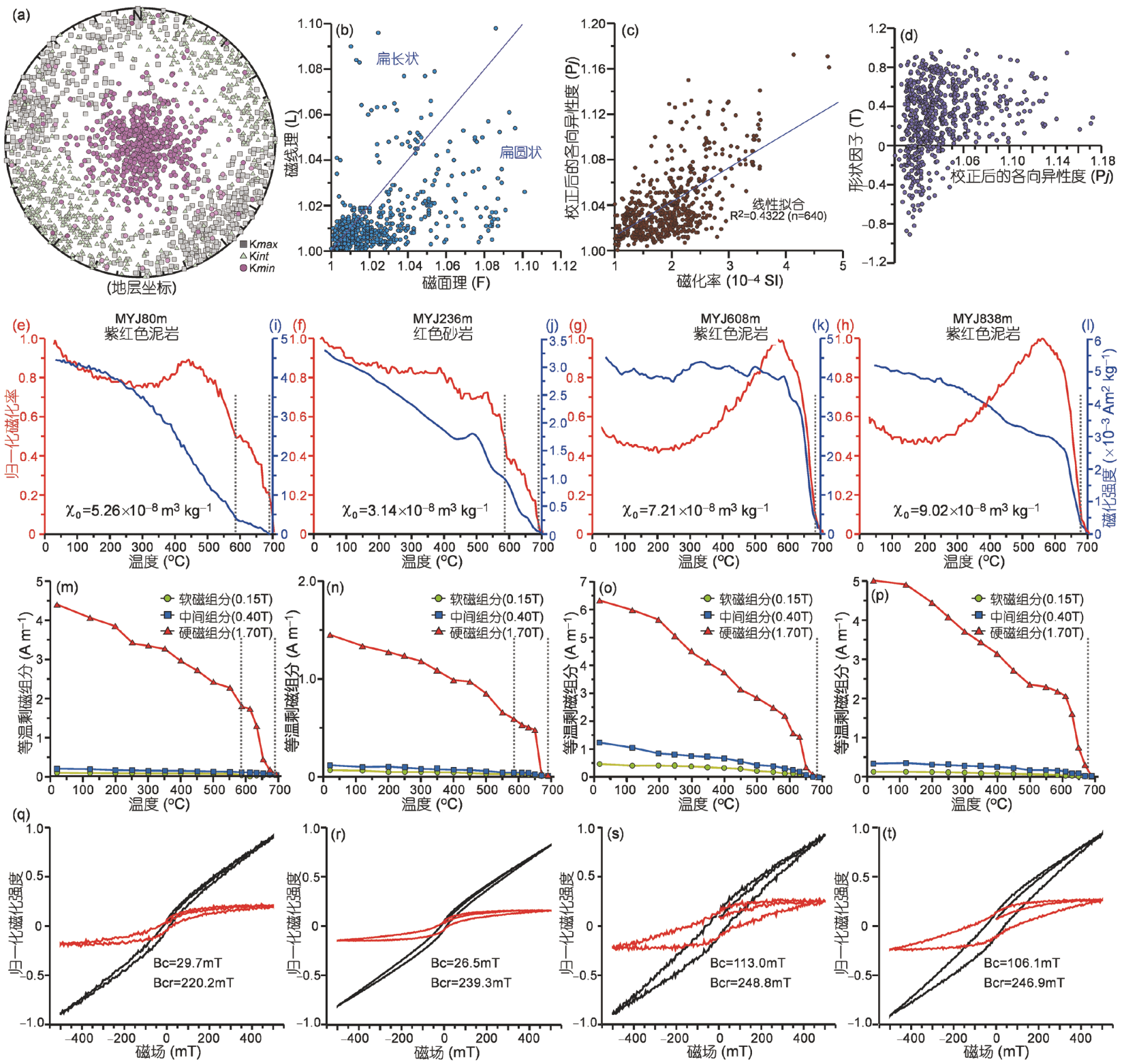

温度 $\left({ }^{\circ} \mathrm{C}\right)$
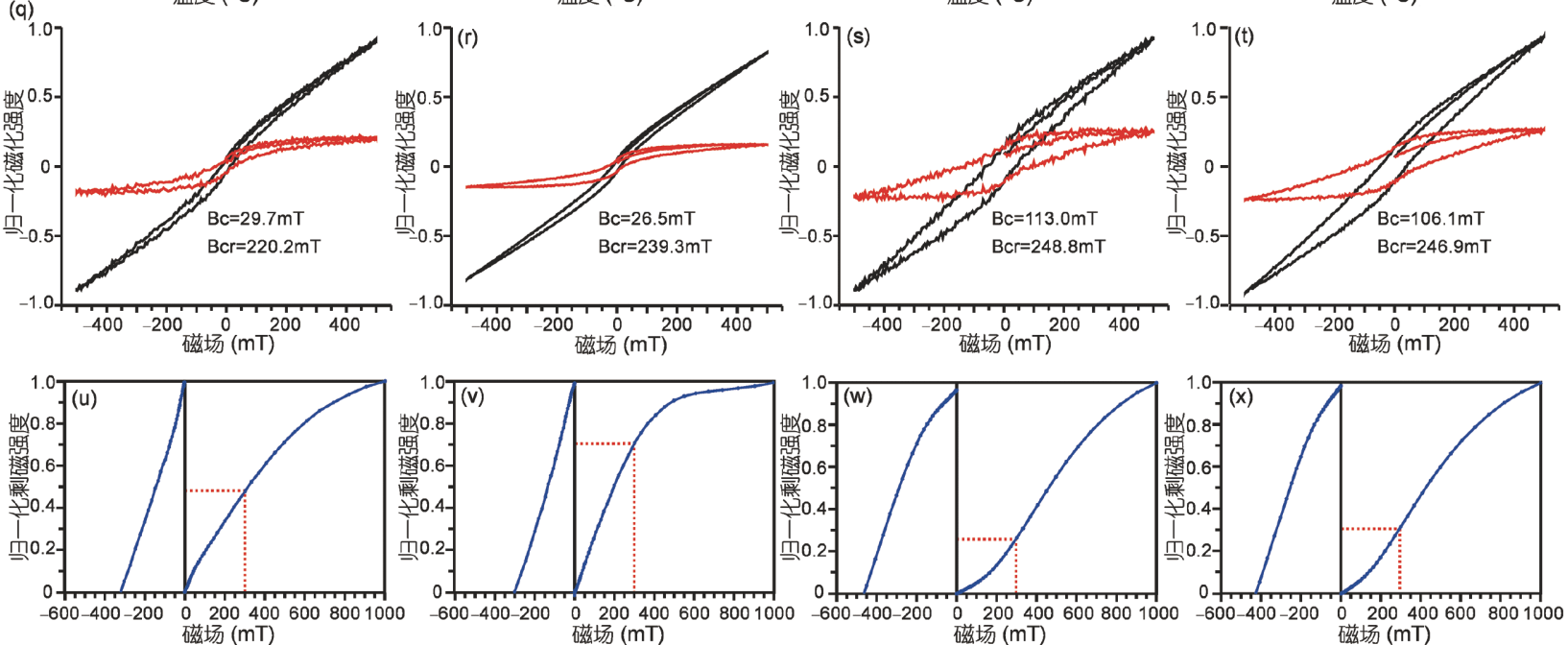

图 3 江城剖面预野井组代表性样品的岩石磁学结果

(a) 磁组构数据的极射赤平投影; (b) 磁面理F和磁线理 L关系; (c) 磁化率和 $\mathrm{P} j$ 关系; (d) P $j$ 和形状因子关系; (e) (h) 典型 $\chi-T$ 曲线; (i) (1) 典型 $M-T$ 曲线; (m) (p) 三轴IRM热退磁曲线; (q) ( $\mathrm{t}$ ) 磁滞回线, 其中红色(黑色)曲线代表顺磁校正前(后)的结果; (u) (x) 等温剩磁获得曲线与反向场退 磁曲线 
等, 1996) (图3q, 3r). 而地层中部和下部的样品磁滞回 线呈粗腰状且具有更高的矫顽力 $(\mathrm{Bc})$ 和剩磁矫顽力 (Bcr) (图3s, 3t), 反映了高矫顽力磁性矿物(如赤铁矿) 占主导地位(Dunlop和Özdemir, 1997).

等温剩磁获得曲线显示所有样品在 $1 \mathrm{~T}$ 时未达到 饱和(图3u 3x), 揭示赤铁矿是主要的磁性矿物, 与上 述认识一致. 当外加磁场为 $300 \mathrm{mT}$ 时, 预野井组上部样 品获得饱和等温剩磁强度的 50 70\%(图3u, 3v), 而地层 中下部的样品少于 $30 \%$ (图3 $\mathrm{w}, 3 \mathrm{x}$ ), 说明预野井组地层 上部沉积物含有更多的软磁性矿物(如磁铁矿). 由上 可知，岩石磁学结果共同表明，赤铁矿是预野井组的 主要载磁矿物, 仅在地层上部同时含有少量的磁铁矿.

岩石学分析显示预野井组紫红色粉砂岩和泥岩表 现为基质支撑，粒径通常小于 $0.05 \mathrm{~mm}$ ，同时在胶结物 中含有少量岩屑(如石英、长石等) (图 $4 \mathrm{a}, 4 \mathrm{c}, 4 \mathrm{~m} \sim 4 \mathrm{p}$ ), 而预野井组上部的红色砂岩主要为碎屑支撑, 粒径分 布在 0.1 0.5mm(图4b, 4d). 在显微镜透射光下未发现 热液活动、高温变质现象或化学重结晶相关的产物 (图4a 4d，4m 4p), 排除了获得热黏滞剩磁的可能 (Kent和Miller, 1987; Jackson, 1990). 磁性矿物如赤铁 矿 (粒径从几微米至 $~ 30 \mu \mathrm{m}$ ) 和磁铁矿 (通常小于 $\sim 15 \mu \mathrm{m}$ ) 多以粒状分布在其他矿物和碎屑颗粒之间(图 $4 \mathrm{e} \sim 4 \mathrm{~h}, 4 \mathrm{q} \sim 4 \mathrm{t}$ ). 背散射(图 $4 \mathrm{e} \sim 4 \mathrm{~h}, 4 \mathrm{q} \sim 4 \mathrm{t}$ ) 和能谱分析(图 $4 \mathrm{i} \sim 41,4 \mathrm{u} \sim 4 \mathrm{x})$ 图像表明这些磁性矿物颗粒成份以Fe和 $\mathrm{O}$ 为主, 并且在这些铁氧化物颗粒边缘未发现矿物变 质或交代作用现象. 上述分析共同表明预野井组古地 磁样品的携磁矿物可能是碎屑成因的单畴、假单畴赤 铁矿和磁铁矿, 能够携带稳定剩磁.

\section{2 古地磁结果和可靠性}

系统热退磁可以从大多数样品中分离出特征剩磁 方向(图5a 50). 低温组分(LTC)一般在200 350 ${ }^{\circ} \mathrm{C}$ 以下 获得, 451 个样品的稳定低温组分在地理和地层坐标下 的平均方向分别为 $D_{\mathrm{g}} / I_{\mathrm{g}}=359.0^{\circ} / 44.1^{\circ}\left(k_{\mathrm{g}}=9, \alpha_{95 \mathrm{~g}}=\right.$ $2.3^{\circ}$ )和 $D_{\mathrm{S}} / I_{\mathrm{S}}=18.8^{\circ} / 28.0^{\circ}\left(k_{\mathrm{S}}=7, \alpha_{95 \mathrm{~S}}=2.6^{\circ}\right)$ (图6a). 其 中，地理坐标下的LTC平均方向接近现今地球磁场方 向(图6a), 未通过禇皱检验(图6b), 很可能为近现代地 磁场的黏滞剩磁方向. 特征剩磁方向由至少四个趋向 于原点的连续退磁步数确定, 退磁紊乱或最大角度偏 差(MAD)超过 $15^{\circ}$ 的结果排除在进一步讨论分析之外. 最终从 857 个样品( $90.4 \%$ )中获得可靠的特征剩磁方
向(网络版附表A1, http://earthen.scichina.com), 其正、 负极性方向的平均值分别为 $D_{\mathrm{n}} / I_{\mathrm{n}}=10.7^{\circ} / 41.2^{\circ}\left(k_{\mathrm{n}}=7.0\right.$, $\left.\alpha_{95 \mathrm{n}}=2.1^{\circ}, n=727\right)$ 和 $D_{\mathrm{r}} / I_{\mathrm{r}}=189.6^{\circ} /-43.0^{\circ} \quad\left(k_{\mathrm{r}}=8.0\right.$, $\alpha_{95 \mathrm{r}}=4.8, n=130$ ) (图6c), 所有结果在地层坐标下的平 均值为 $D_{\mathrm{s}} / I_{\mathrm{s}}=10.5^{\circ} / 41.5^{\circ}\left(k_{\mathrm{n}}=7, \alpha_{95 \mathrm{n}}=1.9^{\circ}, n=857\right)$. 正负 极性特征剩磁方向的平均值在 $95 \%$ 置信水平上不可区 分, 通过 McFadden和McElhinny (1990)B 级 ( $\gamma_{\text {observed }}$ $\left(=2.0^{\circ}\right)<\gamma_{\text {critical }}\left(=5.3^{\circ}\right)$ ) 倒转检验(Tauxe, 1998) (图6d). 同时，从38个褶皱检验样品中获得 34 个有效特征剩磁 方向(图6 e), 通过McFadden (1990) 褶皱检验(地理坐 标下 $\xi_{2}=25.36$, 地层坐标下 $\xi_{2}=1.7,95 \%$ 和 $99 \%$ 临界值 $\xi$ 分别为 6.78 和 9.59 ), 且精度参数在 $91.7 \%$ 的褶皱展平状 态时达到最大(Watson和Enkin, 1993) (图 6f; 网络版附 表A2). 此外, 代表性样品的剩磁强度衰减曲线呈上凸 状(图5p), 指示了碎屑成因的赤铁矿为载磁矿物. 上述 分析说明所获得的特征剩磁方向很可能是原生的地磁 场方向.

所有的 857 个特征剩磁方向用于预野井组地层的 磁极性序列分析. 每个极性带由至少两个连续的同极 性点确定. 共获得7个正极性(N1 N 7) 和7个负极性带 (R1 R7) (图7). 其中, 地层下部近622m主要表现为长 的正极性带(N6、N7), 而地层上部出现多个极性倒转 带(R1 R6).

\section{4 讨论}

\section{1 预野井组的沉积年代}

\subsection{1 区域年代学证据}

由于缺乏可靠的年代学约束, 预野井组地层自 1963年创名以来, 其年代饱受争议. 早期依据地层接 触关系推断属于中侏罗世(云南省地质矿产局，1996). 随后, 来自普洱地区的少量介形类化石组合(如Lycopterocypris angulata, L. cuneata, L. celsa Mongolianella perlucida, Advenocypris sp., Rhinocypris sp., Timiriasevia sp., Quadrocypris sp.和Cyclocypris sp.)约束预野井 组地层时代为晚白严世(云南省地质矿产局, 1976), 同 时，少量被子植物狍粉指示其年代为早白严世晚期至 晚白严世早期(陈乐尧，1980). 自20世纪90年代以来, 随着介形类(Sinocypris, Cypris, Parailyocypris and Porpocypris)和轮藻类植物区系(Obtusochara, Tectochara and Rhabdochara)化石组合的发现, 㐨野井组属于古新 

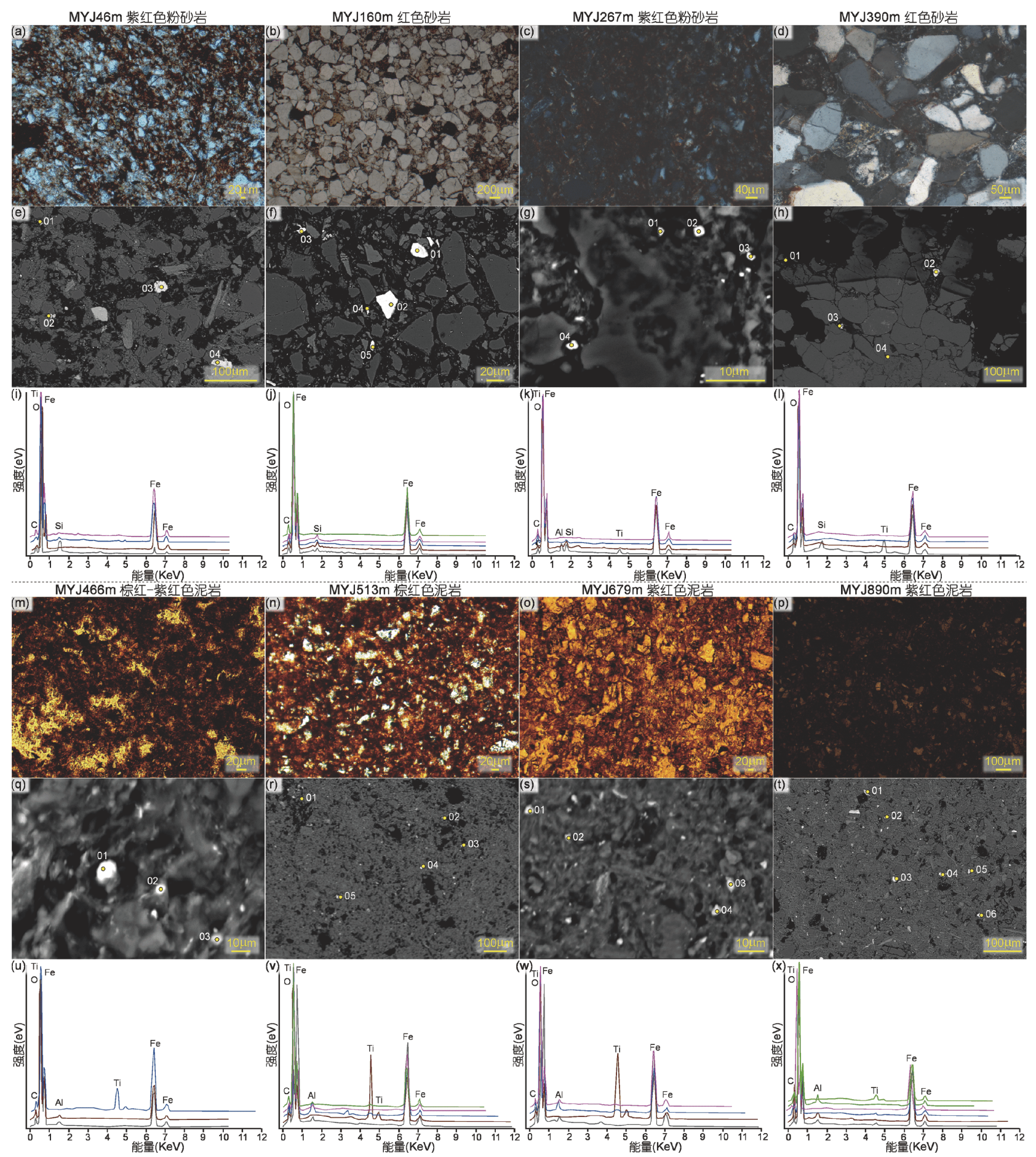

图 4 江城剖面代表性样品显微镜下图像和能谱分析

(a) (d), (m) (p) 岩石薄片在显微镜下的透射光图像; (e) (h), (q) (t) 磁性矿物颗粒的背散射图像, 其中黄色实心点表示能谱分析点位; (i) ( (l), (u) $\sim(\mathrm{x})$ 能谱分析结果 

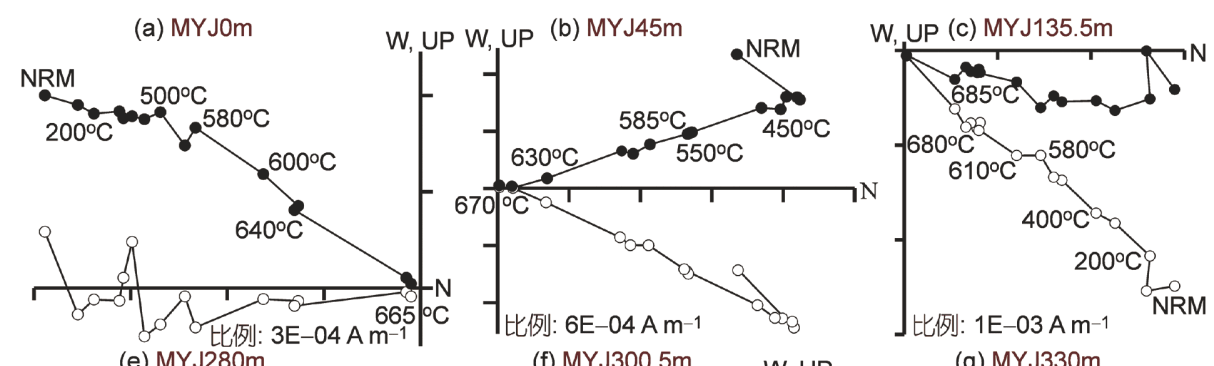

(d) MYJ234m

(e) MYJ280m

(f) MYJ300.5m

(g) MYJ330m
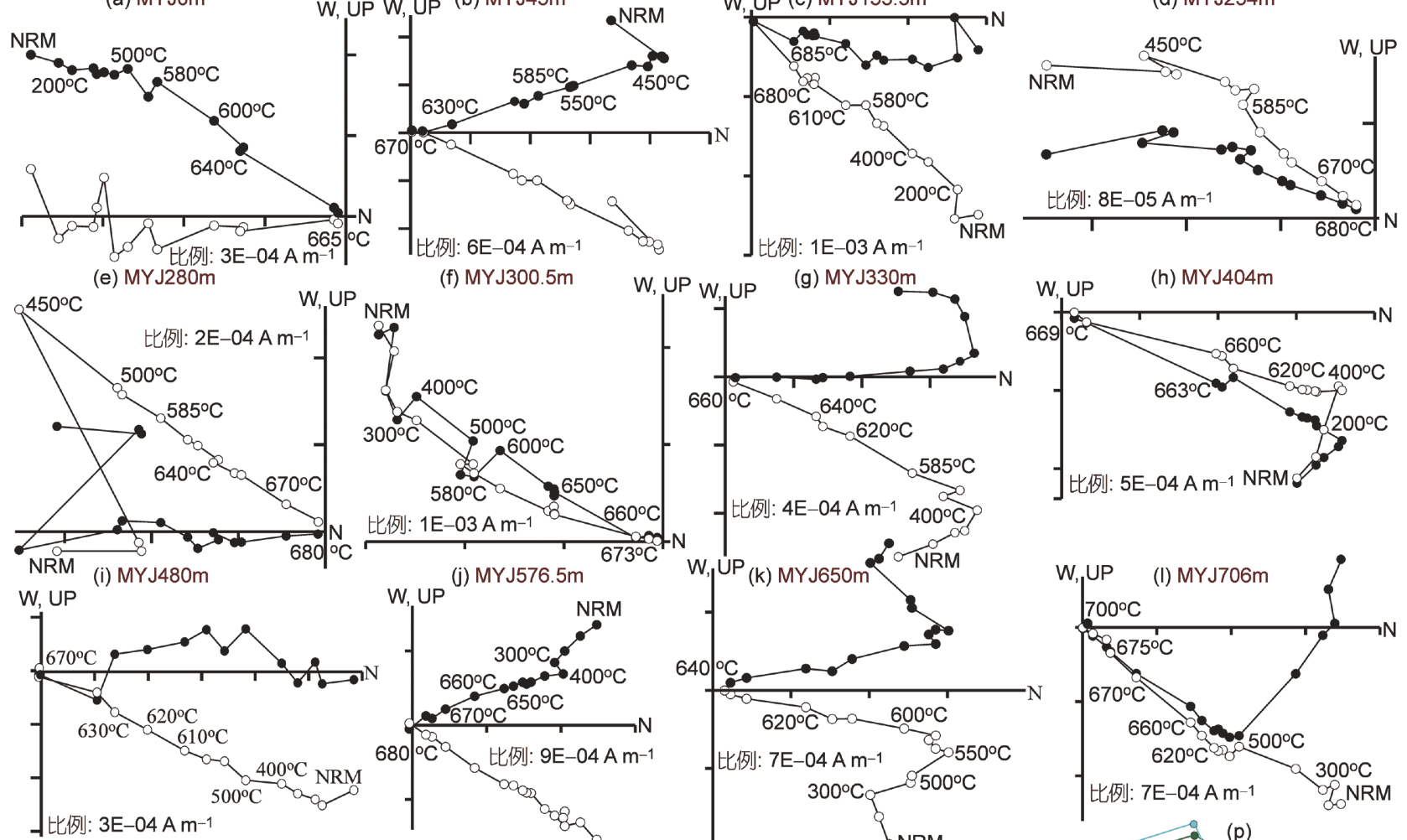

(m) MYJ766m
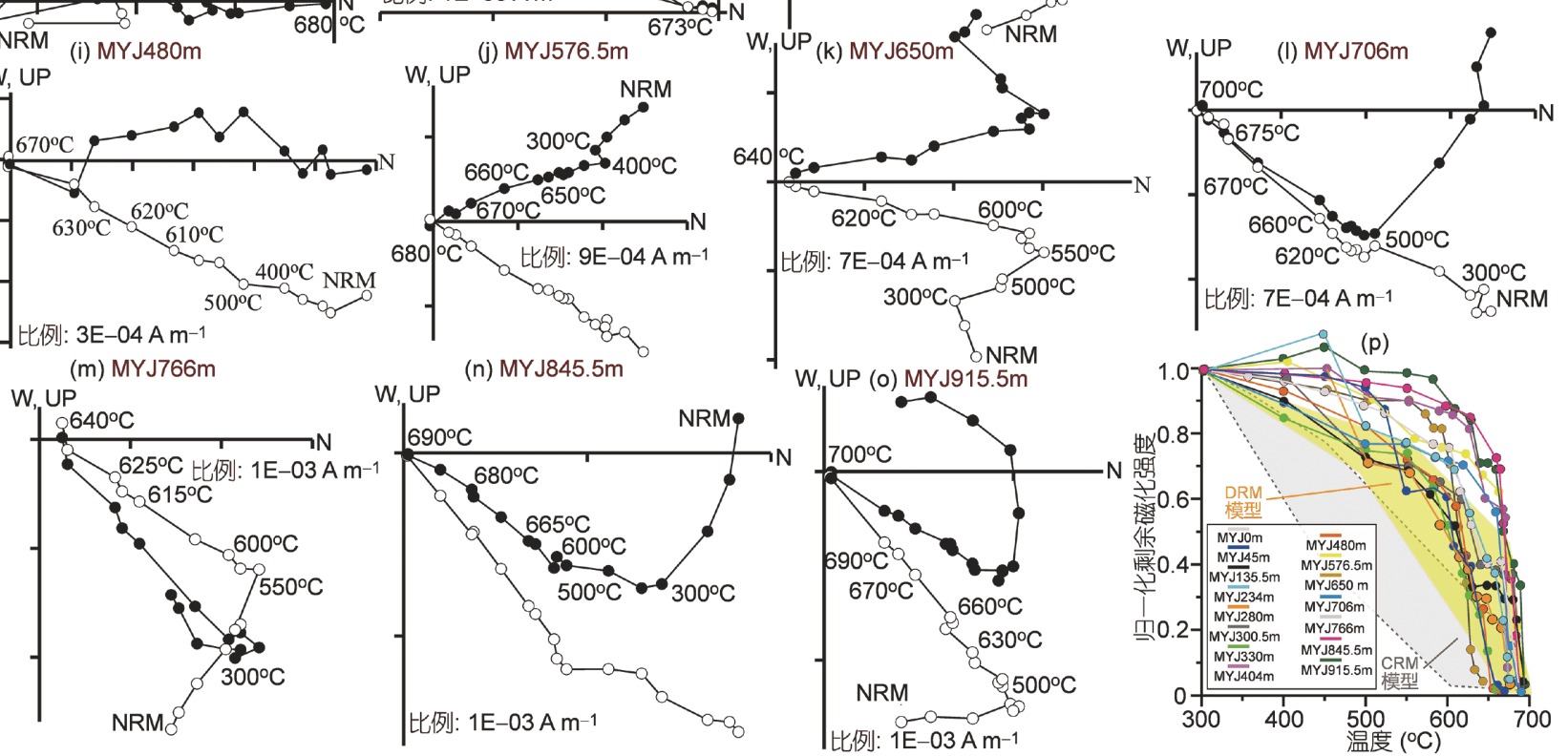

图 5 预野井组代表性样品在地层坐标下的系统热退磁正交投影图((a) (o))和剩磁强度变化图(p)

NRM, 天然剩磁. (p)中黄色和灰色区域分别代表碎屑剩磁模型(DRM)和化学剩磁模型(CRM) (Jiang等, 2015)

统地层逐渐成为了主流观点 (叶春辉和蒋志文, 1981; 云南省地质矿产局, 1996; 曲懿华等, 1998). 然而, 近期 针对宝藏乡预野井钾盐矿区(图1b)670m厚含盐系地层 的孢粉分析得到狍粉组合Psophophaera-Exesipollenites-Classopollis，且发现单沟类Monoclopopollenites 和三沟类Tricopite等被子植物花粉，将预野井组地层 限定为早白严世的阿普第期-阿尔布期(袁秦等，2013) 或阿普第期-塞诺曼期(Wang等，2015); 此外，来自宝 藏乡预野井组地层凝灰岩层的高精度SHRIMP U-Pb 定年结果为 110 100Ma, 指示预野井组地层年代系早
白严世晚期 晚白严世(Wang等, 2015) (图8b). 因此, 基 于上述结果特别是近期的孢粉组合特征(袁秦等, 2013)和直接的绝对同位素年代学分析 (Wang 等, 2015), 㐨野井组地层的年代应属于早白严世晚期至古 新世.

\subsection{2 最年轻碎屑锆石 $\mathrm{U}-\mathrm{Pb}$ 年龄}

最年轻碎屑锆石 $\mathrm{U}-\mathrm{Pb}$ 年龄被广泛用于限定沉积 物的最大沉积年龄(如Nelson，2001；Fildani等，2003; Dickinson和Gehrels, 2009; Horton等, 2015; Sharman和 


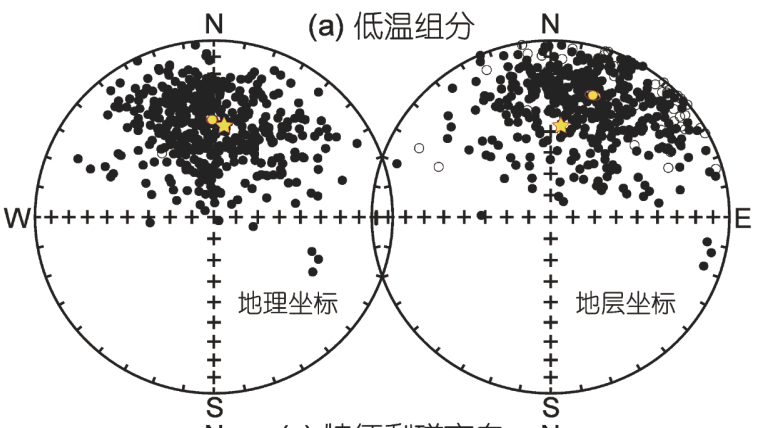

(c) 特征剩磁方向 N (b)

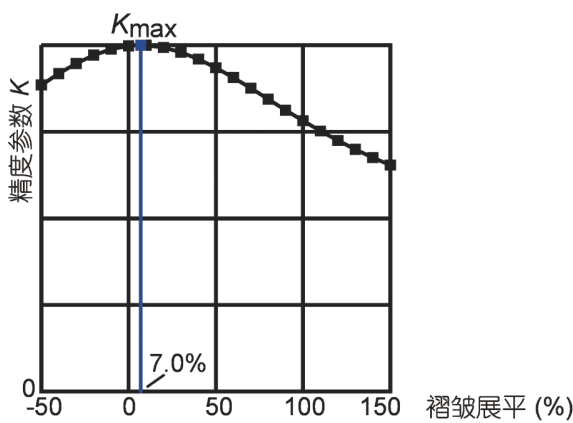

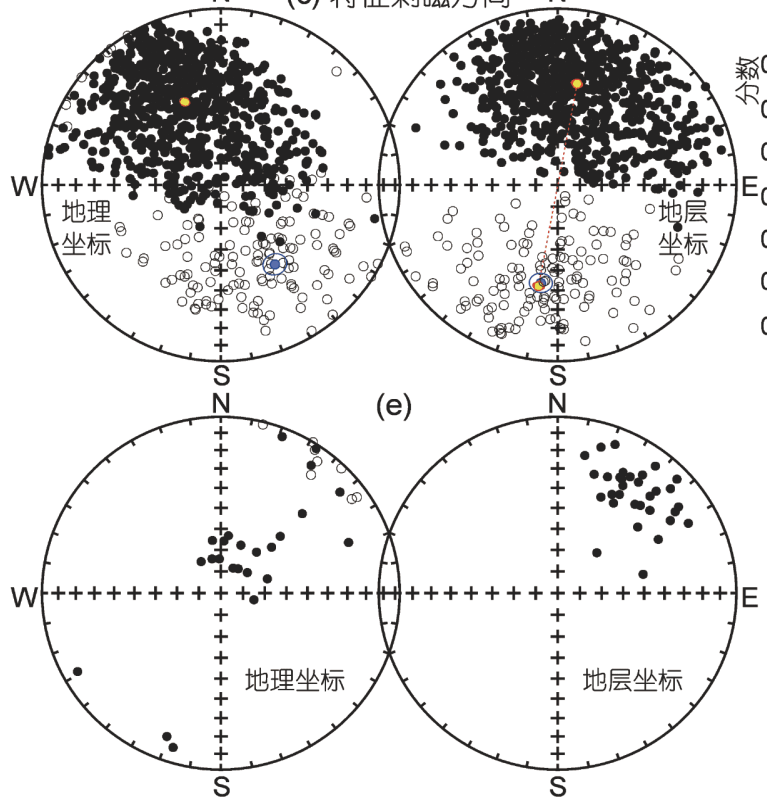

(d)

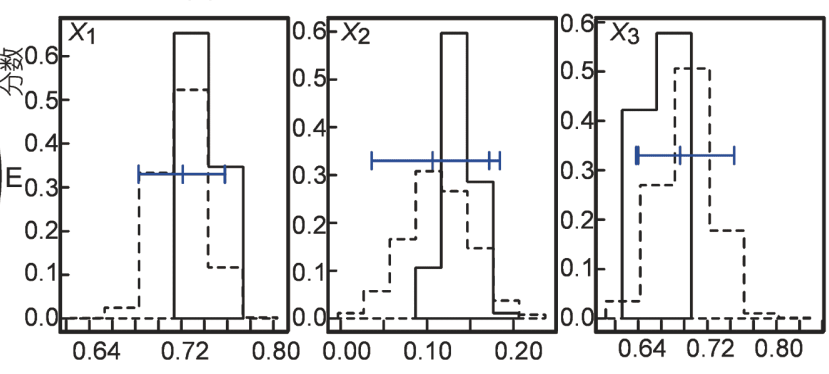

(f)

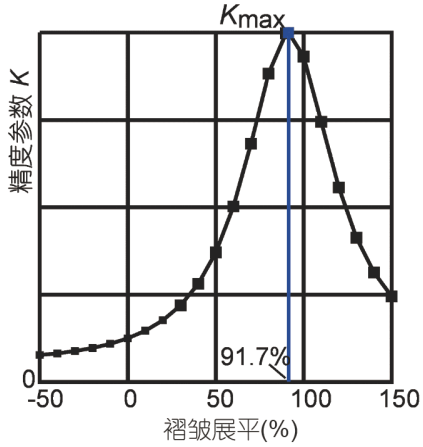

图 6 预野井组古地磁投影及检验结果

(a) 低温组分 (LTC)等积投影; (b) Watson和Enkin (1993)褶䏢展平检验结果. 特征剩磁方向(ChRMs)等积投影(c)和Tauxe (1998)倒转检验结果(d). 负极性古地磁方向被倒转至它们的对趾点，所有组分在 $95 \%$ 置信区间内重叠，表明通过倒转检验. 褟皱检验样品的特征剩磁方向等积投影( $)$ 和褔铍展平检验结果(f). 图中黄色(蓝色)实心圆表示 $95 \%$ 置信限下的平均方向

Malkowski, 2020). 本文依据Dickinson和Gehrels(2009), 利用三种方法确定最年轻碎屑锆石年龄(表1)，按照统 计可靠性由低到高，包括最年轻的单个锆石颗粒年龄 (YSG)，最年轻的图表年龄峰值(YPP)和至少两颗最年 轻锆石颗粒年龄的加权平均值 $(\mathrm{YC} 1 \sigma(2+))$. 图9显示了 最年轻单颗粒锆石(数据详见附表A3)的代表性阴极发 光(CL)图像和U-Pb谐和图. 对于样品MYJ-55和MYJ900 , 三种方法获得的年龄一致, 两个样品的 $\mathrm{YC} 1 \sigma(2+)$ 值分别为 $(82.2 \pm 0.88) \mathrm{Ma}(\mathrm{MSWD}=0.80)$ 和(122.4 \pm 6.1$)$ $\mathrm{Ma}(\mathrm{MSWD}=0.02)$, 被用来约束江城剖面 $55 \mathrm{~m}$ 和 $900 \mathrm{~m}$ 处的最大沉积年龄(表1). 而对于样品MYJ-300和MYJ600 , 其YPP值分别为 $(93 \pm 2)$ 和 $(109 \pm 1) \mathrm{Ma}$ ，被用于限定
江城剖面 300 和 $600 \mathrm{~m}$ 处的最大沉积年龄. 由此, 江城剖 面900、600、300和 $55 \mathrm{~m}$ 处的沉积年龄分别不早于 122.4、109.5、93.8和82.2Ma (图7; 表1)，与前述孢粉 组合和凝灰岩年代基本一致.

\subsection{3 预野井组磁性地层年代}

在上述最年轻碎屑锆石 $\mathrm{U}-\mathrm{Pb}$ 年龄、区域化石和 凝灰岩层SHRIMP U-Pb年代学结果共同约束下, 开展 所获得预野井组极性序列与国际标准极性柱 (GPTS2012) (Gradstein等, 2012)的对比. GPTS2012在 早白严世晚期至古新世以白严纪超长正极性期 (CLNS；125.93 83.64 Ma) 和频繁倒转阶段 


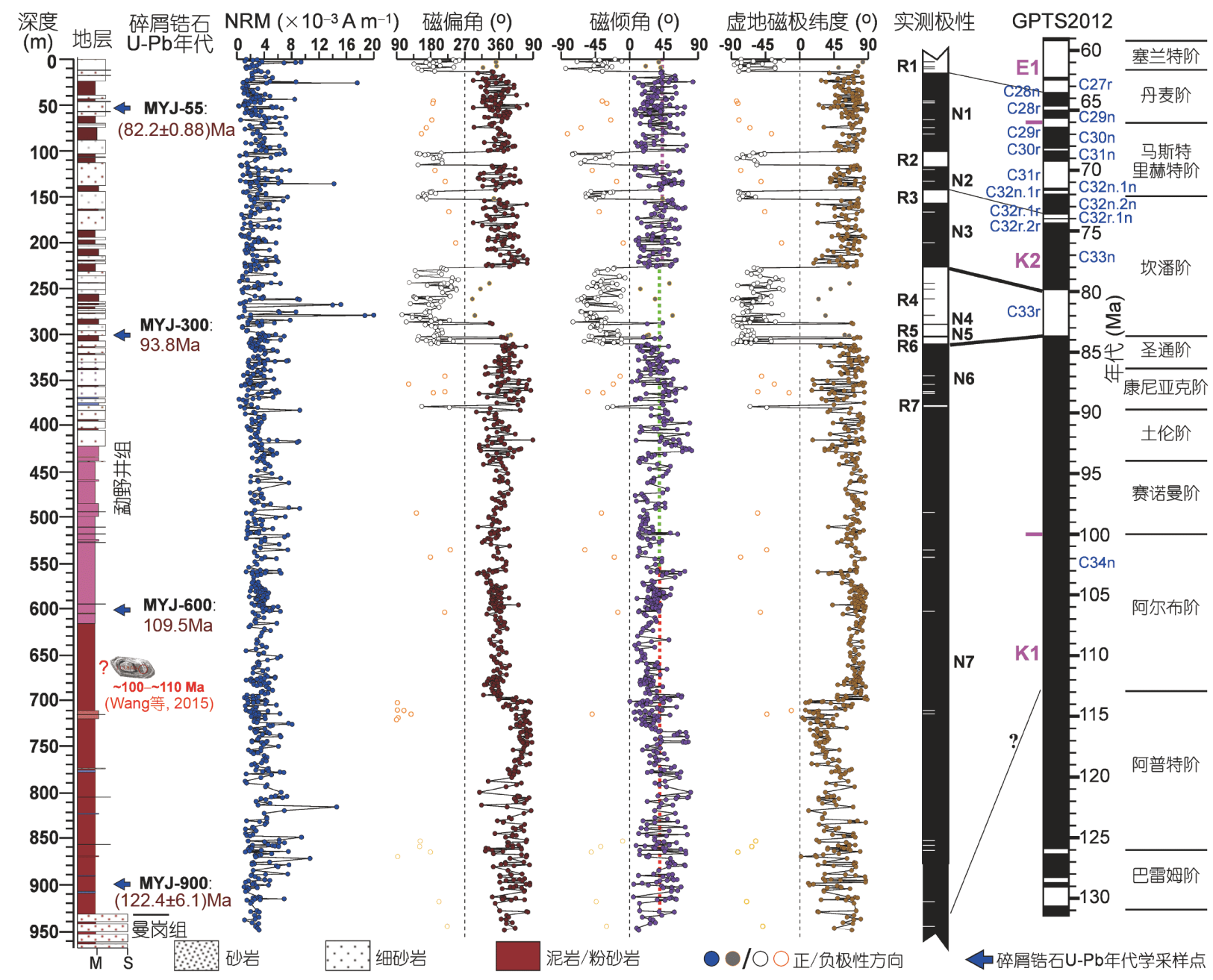

图 7 预野井组地层岩性和磁极性序列及其与GPTS2012的对比

四个碎屑锆石 $\mathrm{U}-\mathrm{Pb}$ 年代表示最年轻锆石年龄结果 (详见表1), 可以提供相应层位沉积年龄的下限. 凝灰岩层SHRIMP U-Pb年代来自Wang等 (2015), 但它在㐨野井组地层中的具体层位及其与江城剖面的比对并不清楚. 图中红色、蓝色和紫色虚线分别表示相应区间的磁倾角平均值

表 1 江城剖面㔚野井组不同层位的最大沉积年龄和对应的磁性地层年代

\begin{tabular}{|c|c|c|c|c|c|c|c|c|c|}
\hline 样品号 & 岩性 & 厚度 $(\mathrm{m})$ & $\begin{array}{c}\text { 测试锆石 } \\
\text { 颗粒数 }\end{array}$ & $\begin{array}{c}\text { 年轻的单颗粒锆石 } \\
\text { 年龄 }(\mathrm{Ma}, 1 \sigma)\end{array}$ & YSG $(\mathrm{Ma}, 1 \sigma)$ & YPP (Ma) & $\begin{array}{c}\mathrm{YC} 1 \sigma(2+) \\
(\mathrm{Ma})\end{array}$ & $\begin{array}{c}\text { 最大沉积年 } \\
\text { 龄 }(\mathrm{Ma}) \\
\end{array}$ & $\begin{array}{c}\text { 磁性地层年 } \\
\text { 代 (Ma) }\end{array}$ \\
\hline MYJ-55 & 细砂岩 & 55 & 120 & $77 \pm 1,82 \pm 1,83 \pm 2$ & $77 \pm 1$ & 81.9 & $82.2 \pm 0.88$ & $82.2 \pm 0.88$ & $\sim 68$ \\
\hline MYJ-300 & 细砂岩 & 300 & 130 & $93 \pm 2,98 \pm 1$ & $93 \pm 2$ & 93.8 & - & 93.8 & $\sim 83$ \\
\hline MYJ-600 & 粉砂岩 & 600 & 140 & $109 \pm 1,113 \pm 2$ & $109 \pm 1$ & 109.5 & - & 109.5 & $\sim 97$ \\
\hline MYJ-900 & 粉砂岩 & 900 & 120 & $122 \pm 4,123 \pm 5$ & $122 \pm 4$ & 122.5 & $122.4 \pm 6.1$ & $122.4 \pm 6.1$ & $\sim 110.5$ \\
\hline
\end{tabular}

(83.64 65Ma)为特征. 为此, 将笻野井组中下部观测到 的长的正极性带(N6-N7)与CLNS对比, 而R4-R6、R3$\mathrm{N} 3$ 和 R1-N2 分别与 C33r、C32r.1r-C33n和C27rC 32n.2n对比(图7). 由于预野井组底部仍然是正极性
(N7), 无法准确限定其与CLNS的对比. 本文假设江城 剖面N6-N7段与 R 4 R 6 段具有相同的沉积速率 $\left(\sim 2.23 \mathrm{~cm} \mathrm{ka}^{-1}\right)$, 由此初步约束预野井组地层底部的沉 积年代为 $112 \mathrm{Ma}$. 上述对比方案首次获得了云南含钾 

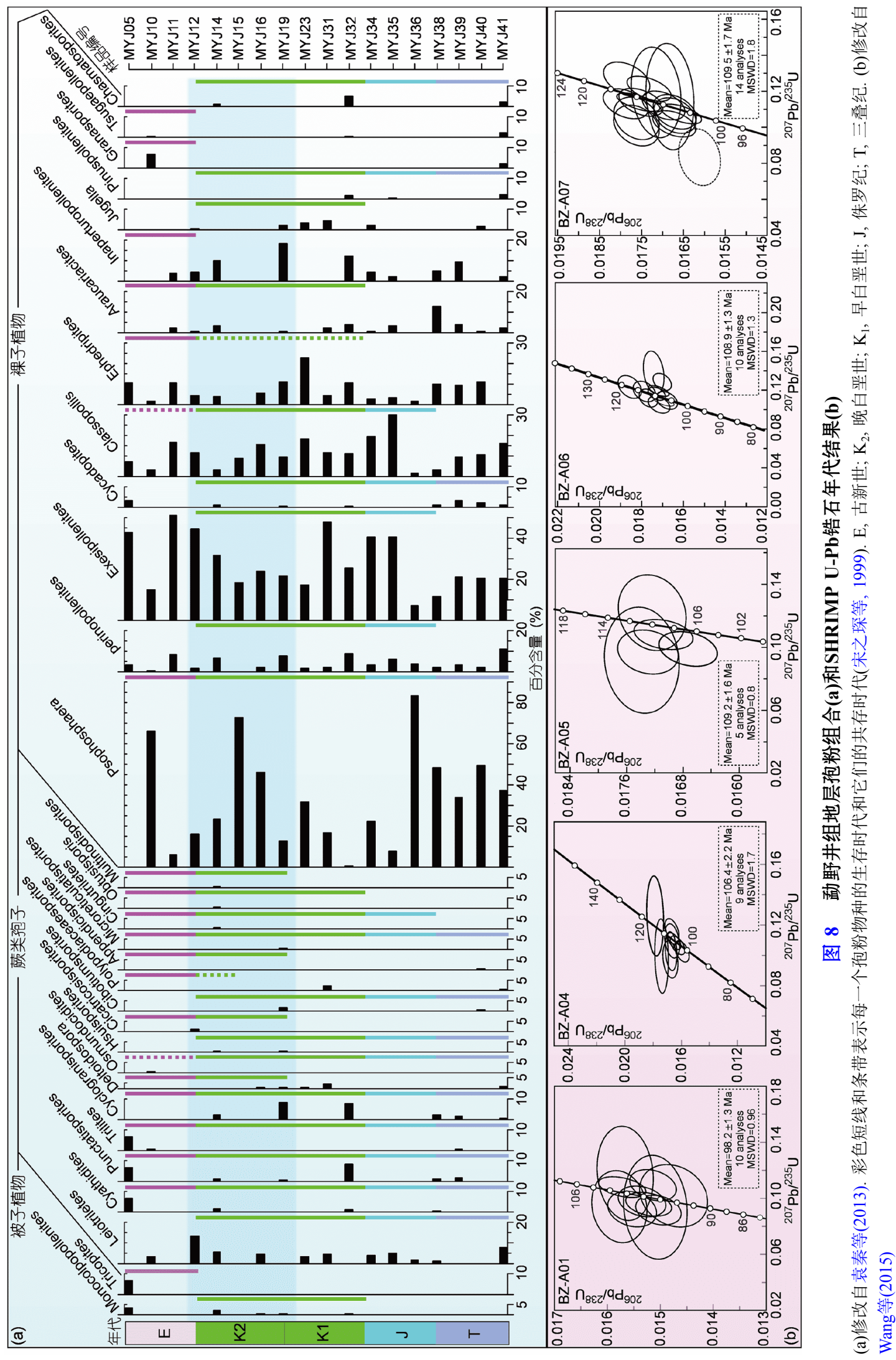

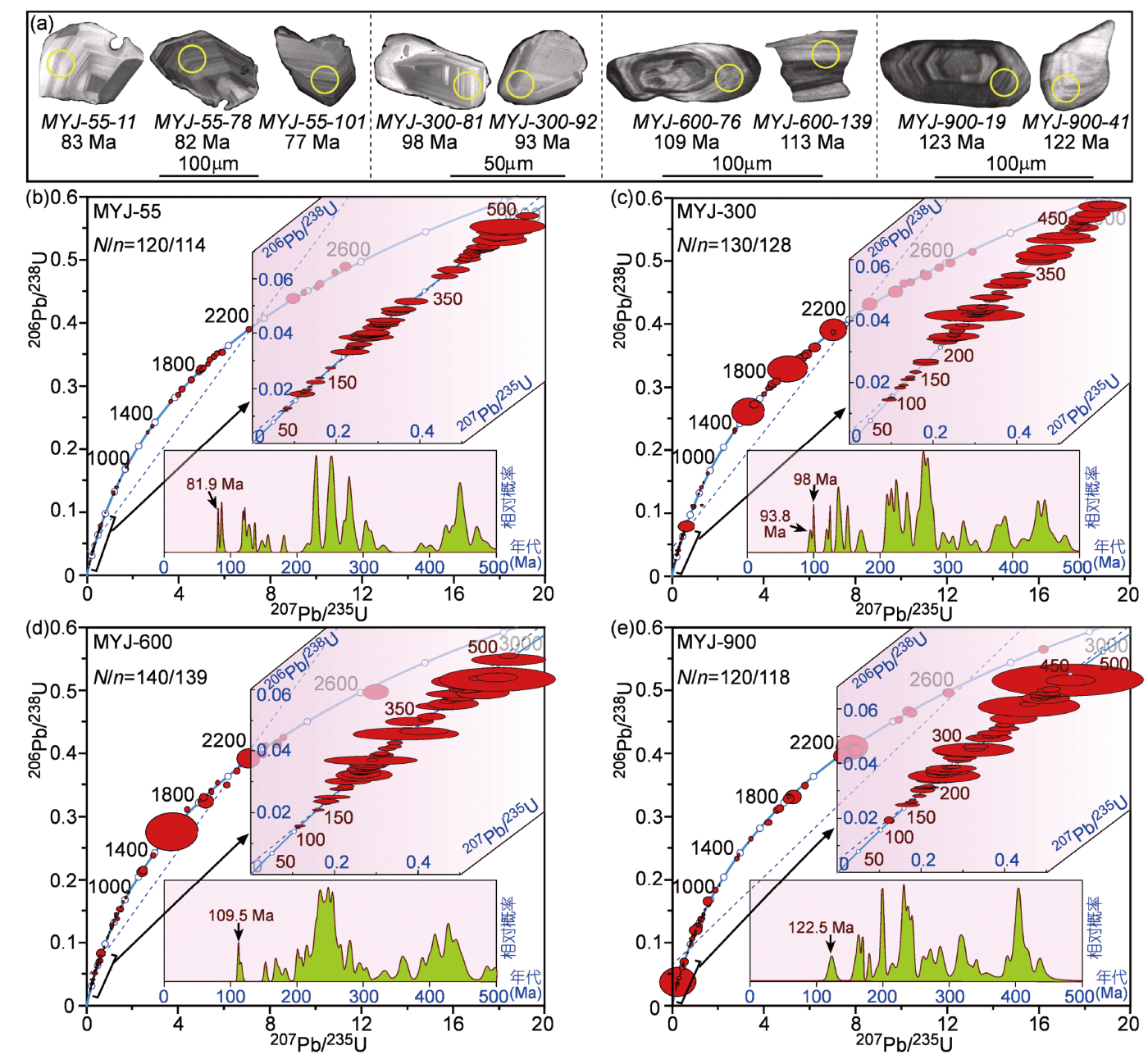

图 9 样品锆石的CL图像、U-Pb年龄以及相应的U-Pb年代谐和图

(a) 江城剖面四件样品(MYJ-55、MYJ-300、MYJ-600、MYJ-900)的代表性最年轻锆石CL图像和U-Pb年龄，图中标注了分析点位、编号 与 ${ }^{206} \mathrm{~Pb} /{ }^{238} \mathrm{U}$ 年龄. (b) (e) 相应锆石的U-Pb年代谐和图. $N / n$ 表示用于U-Pb分析的锆石颗粒数和有效年龄数; 插图显示了 $0 \sim 500 \mathrm{Ma}$ 碎屑锆石年 龄频率分布图

盐地层预野井组详细的磁性地层年代序列为 $>112 \sim 63 \mathrm{Ma}$; 同时, 预野井组上、中和下段的沉积年代 分别为112 97.4、97.4 88.7和88.7 63Ma. 其中, 预野 井组地层900、600、300和 $55 \mathrm{~m}$ 处的磁性地层年代分 别为 110.5、 97.0、 83.0和 68.0Ma，与通过最年轻 碎屑锆石年龄获得的最大沉积年龄 (122.4 12.1$)$ 、 109.5、93.8和(82.2 \pm 0.9$) \mathrm{Ma}$ (图7; 表1)是一致的，进一 步说明上述对比方案应是合理的.

\section{2 与呵叻盆地马哈萨拉堪组年代对比}

自 20 世纪60年代以来, 预野井和呵叻钾盐矿的关 系一直是相关研究的热点(曲懿华, 1997; Wang等,
2014). 尽管两者的对比关系尚不明确，诸多研究显示 它们具有相似的矿床类型、矿物组合、微量元素、沉 积环境和成钾物质来源(夏文杰和李秀华，1983; 曲懿 华, 1997; 牟传龙等, 1999; 郑绵平等, 2006; 韩元红等, 2011; Li等, 2015; 苗忠英等, 2019), 可能形成于一个连 通的泛盆地(曲懿华等, 1998). 基于新获得古地磁结果, 本文下面对预野井组和马哈萨拉堪组地层的古纬度和 年代开展对比分析.

思茅和呵叻盆地位于特提斯构造域东南端(图1a). 呵叻盆地含钾盐地层马哈萨拉堪组不整合于下伏呵叻 群砂岩之上(Zhang等, 2018), 被认为与预野井组具有 相似的沉积层序(曲懿华, 1997). 马哈萨拉堪组主要包 
括三个浅湖-半深湖相蒸发岩-碎屑岩层序，如下盐层 的基底硬石亳、石盐、钾盐和碎屑物质，中盐层的石 盐和粉砂岩, 以及上盐层的石盐和硬石膏夹层(曲懿 华, 1997; El Tabakh等, 1999); 而思茅盆地预野井组地 层等同于马哈萨拉堪组的中-下盐层，缺失上盐层(曲 懿华, 1997). 因此, 许多研究认为这两个盆地的钾盐 矿可能具有密切的古地理关系(曲懿华，1997; 曲懿华 等, 1998; Wang等, 2014, 2015).

呵叻盆地蒸发岩地层马哈萨拉堪组年代存在从早 白严世到始新世的争议(图10). 该组在创名之初被划 分为早白严世-始新世地层(Gardner等，1967; Suwanich, 1986), 随后基于少数比较初步的磁性地层结果 将其归为晚白严世地层(如Maranate，1982; Maranate 和Vella, 1986), 介形类和轮藻化石组合则认为其应为 古新世地层(冯明刚等, 2005), 但孢粉组合特征则指示 其为早白严世阿尔布期至晚白严世塞诺曼期(Harris, 1977; Racey和Goodall，2009)或晚白严世土伦期至圣 通期(钟晓勇等, 2012; 秦占杰等, 2013)地层; 另外, 针 对地层中石盐、硬石膏、光卤石和黏土样品的多种同 位素定年方法限定地层中蒸发岩的形成年代分别为晚 白严世塞诺曼期(Pisutha-Arnond等，1986; Hansen等, 2002)或圣通期至坎潘期(Hansen等，2016). 最近, Zhang等(2018)针对呵叻盆地东部老挝中部他曲地区 的钻孔(ZK2893)岩芯开展了详细的磁性地层学研究, 结合区域已有的狍粉、同位素和沉积学证据, 约束含 钾盐地层的年代序列为 92 至 $>63.5 \mathrm{Ma}$, 其中, 下、中、 上碎屑层-盐层的年代分别为 92 至 $<80$ 、 $<80$ 至 68.5 和 68.5 至 $>63.5 \mathrm{Ma}$ ，下盐层中的钾盐层地层年代大致在 $\sim 85 \mathrm{Ma}$ (Zhang等, 2018).

上述磁性地层结果揭示预野井组和马哈萨拉堪组 地层的磁性地层年代分别为 $>112$ 至 63 和 92 至 $>63.5 \mathrm{Ma}$, 表明前者比后者至少早开始沉积 $20 \mathrm{Ma}$ ，二者的年代仅 部分重叠(马哈萨拉堪组等同于预野井组的中、上部) 且并不完全一致(图10). 二者都是由三个沉积旋回组 成(图11), 其中, 㐨野井组地层的下、中、上旋回年代 分别为112 97.4、97.4 88.7和88.7 63Ma, 而马哈萨拉 堪组地层的对应年代分别为 92 至 $<80 、<80$ 至 68.5 和 68.5 至 $>63.5 \mathrm{Ma}$, 因此两个盆地含钾盐地层的三个旋回 沉积年代具有明显的差异(图11)。这明显不同于预野 井组等同于马哈萨拉堪组中下部的传统认识(曲懿华 等，1998). 同时，钻孔资料表明预野井组地层的下部
(112 97.4Ma)和上部(88.7 63Ma)具有较好的成钾显 示(曲懿华等, 1998), 而在马哈萨拉堪组下盐层的顶部 蕴藏有厚的钾盐层( 85Ma). 因此, 有必要对两个盆地 钾盐矿之间的关系和它们的成矿机制等进行重新 思考.

\section{3 地质意义}

考虑到大型钾盐成矿是构造、气候和物源三要素 耦合作用的产物，即在特定的构造环境、构造凹地、 长期干旱气候和持续海水补给条件下(Warren, 2010; 刘成林等, 2015; Liu等, 2018), 因此有必要从古地理 (盆地关系)和古气候环境重新审视思茅与呵叻盆地钾 盐矿的关系.

\subsection{1 古地理}

(1) 古纬度. 古纬度可以限定盆地的古地理位置, 进而可以约束盆地间的相对关系. 本文利用新获得和 已有古地磁数据尝试恢复两个盆地在白严纪期间的古 纬度位置.

江城剖面预野井组地层下段(932 553m)、中段 (553 227m) 和上段 $(227 \sim 0 \mathrm{~m})$ 的平均磁倾角分别为 $41.9^{\circ}$ $\left(\alpha_{95}=3.4^{\circ}\right) 、 39^{\circ}\left(\alpha_{95}=3.2^{\circ}\right)$ 和 $42.7^{\circ}\left(\alpha_{95}=3.2^{\circ}\right)$, 与从华南陆 块早白严世 $\left(79^{\circ} \mathrm{N}, 208.3^{\circ} \mathrm{E}, \alpha_{95}=5.9^{\circ}\right)$ (黄宝春等, 2008 ) 和晚白严世 $\left(74.3^{\circ} \mathrm{N}, 205.1^{\circ} \mathrm{E}, \alpha_{95}=5.5^{\circ}\right.$ ) (Yang和Besse, 2001)参考极得到的期望磁倾角值一致，可能说明研究 区在预野井组沉积期间(112 63Ma)古纬度总体位于 $22^{\circ}$ $\sim 24.8^{\circ} \mathrm{N}$. 预野井组平均磁倾角为 $41.5^{\circ}$, 对应古纬度值 为 $23.9^{\circ} \mathrm{N}$, 与已报道的古纬度结果 $(20.5+9.3 /-7.6)^{\circ} \mathrm{N}$ (杨 振宇等, 2001)和(17.0+5.6/-5.0) ${ }^{\circ} \mathrm{N}$ (Li等, 2017) (附表A4) 在误差范围内没有差别. 这些结果共同表明思茅盆地 在预野井组沉积期间位于 $17^{\circ} \sim 25^{\circ} \mathrm{N}$. 同时, 磁性地层结 果也揭示呵叻盆地东部他曲地区在92 63Ma期间磁倾 角总体变化不大, 平均古纬度为 $19.4^{\circ} \mathrm{N}$ (Zhang 等, 2018), 与思茅盆地基本在同一纬度上.

同样，来自思茅盆地含钾盐地层下伏景星组、南 新组、虎头寺组(如Kondo等, 2012; Tong等，2013; Gao等, 2015)和呵叻盆地呵叻群(如Charusiri等, 2006; Singsoupho等，2014)地层的古地磁结果(网络版附表 A4)表明两个盆地早白严世均位于 $20^{\circ} \sim 30^{\circ} \mathrm{N}$. 因此, 可 以得出思茅与呵叻盆地在整个白严纪期间大致都位于 $20^{\circ} \sim 30^{\circ} \mathrm{N}$, 处于副热带高压的影响下. 


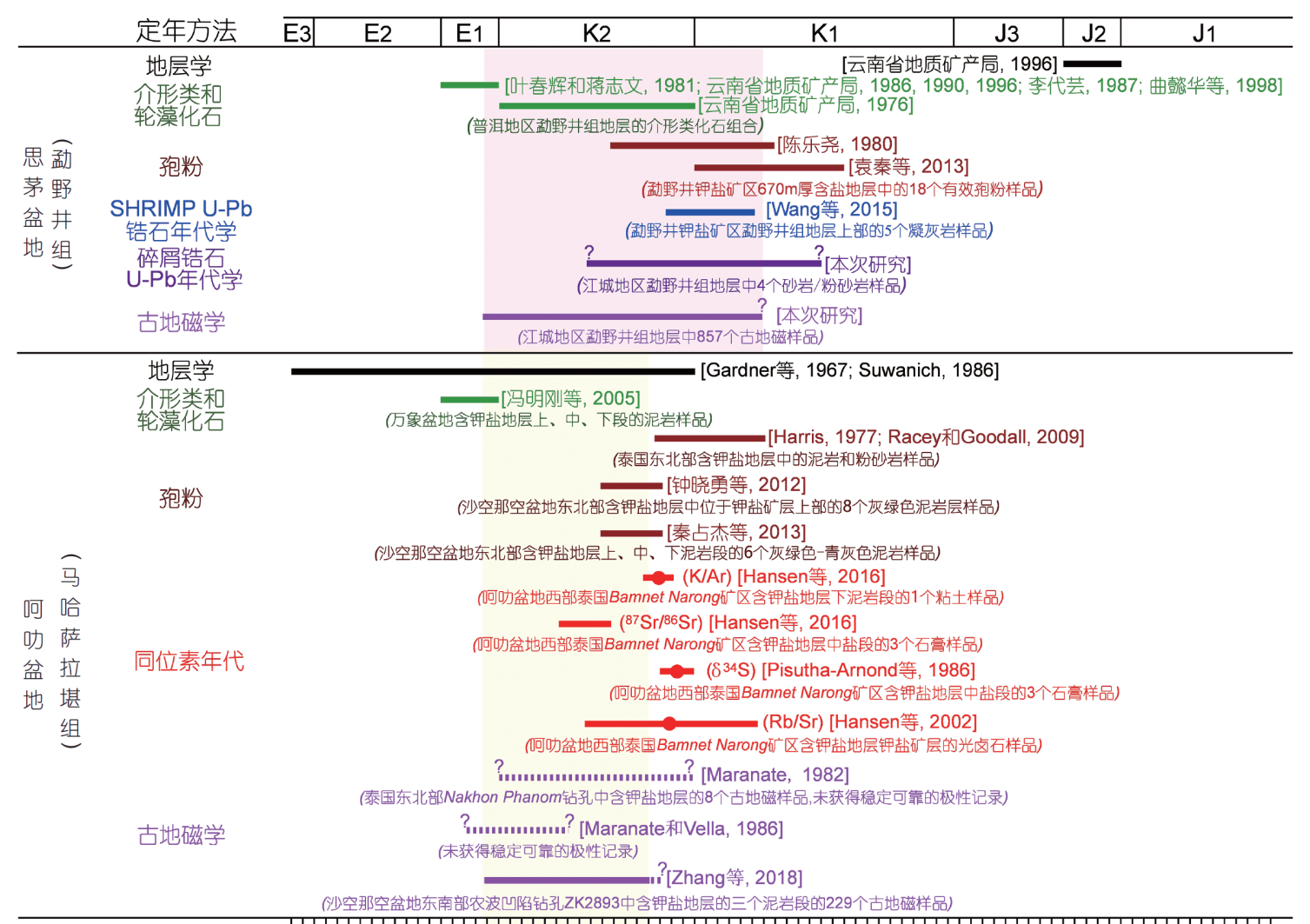

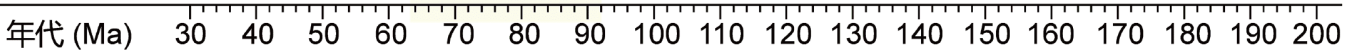

图 10 思茅盆地预野井组和呵叻盆地马哈萨拉堪组地层年代学综合对比

此外，显生宙古纬度分析揭示思茅与印支陆块至 少在晚三叠世可能已经拼贴在一起(如Li等, 2004), 在 白严纪具有相似的顺时针旋转模式和近东西向的古方 位(如Li等, 2004; Tong等, 2013; Li S H等, 2017), 指示 两个陆块在白严纪可能形成一个整体. 这种背景下, 在 思茅与呵叻地区具备存在一个潜在的大范围泛盆地 条件.

（2）构造框架，沉积环境和物源. 构造和物源背景 是约束盆地关系的两个重要因素. 思茅与呵叻盆地同 位于特提斯构造域东南缘(图1b)，二者在中生代经历 了相似的演化历史，如中三叠世至晚三叠世的裂谷阶 段、中侏罗世至晚白严世的沉降和裂陷阶段(Sengör 和Natal'in, 1996; Liu等, 2018). 这两个阶段都与古、中 特提斯洋的闭合密切相关，可能为区域成盐成钾创造 了重要的构造条件.

呵叻与思茅盆地含钾盐地层(马哈萨拉堪组、预 野井组)总体具有相似的沉积环境，包括下盐层的基底
硬石膏、石盐、钾盐和碎屑沉积, 以及中盐层的石盐 和粉砂岩. 此外, 马哈萨拉堪组还沉积了上盐层的石 盐和薄层硬石膏层(曲懿华, 1997; El Tabakh等, 1999). 含钾盐地层的下伏地层主要表现为侏罗纪-早白严世 河流相-冲积相砂岩-泥岩层序和海陆交互相沉积, 部 分层位含有少量蒸发岩层(云南省地质矿产局，1996; 郑绵平等, 2014).

已有碎屑锆石 $\mathrm{U}-\mathrm{Pb}$ 年代学数据表明思茅盆地预 野井组与呵叻盆地含钾盐地层下伏呵叻群可能具有相 似的沉积物源 (图12). 包括晚二叠世-三叠纪的松潘-甘 孜、中三叠世-晚三叠世的可可西里、晚三叠世-侏罗 纪的北芫塘、三叠纪的南芫塘和元古代的西扬子等可 能都为两个盆地含钾盐地层提供了沉积物源. 因而, 两 个盆地在白严纪可能具有一致的物源区.

综上，思茅与呵叻盆地相似的古纬度演化历史、 构造背景、沉积环境和物源分析以及广泛报道的二者 钾盐矿相似的矿物学特征(曲懿华, 1997; 曲懿华等, 
(a) 思茅盆地

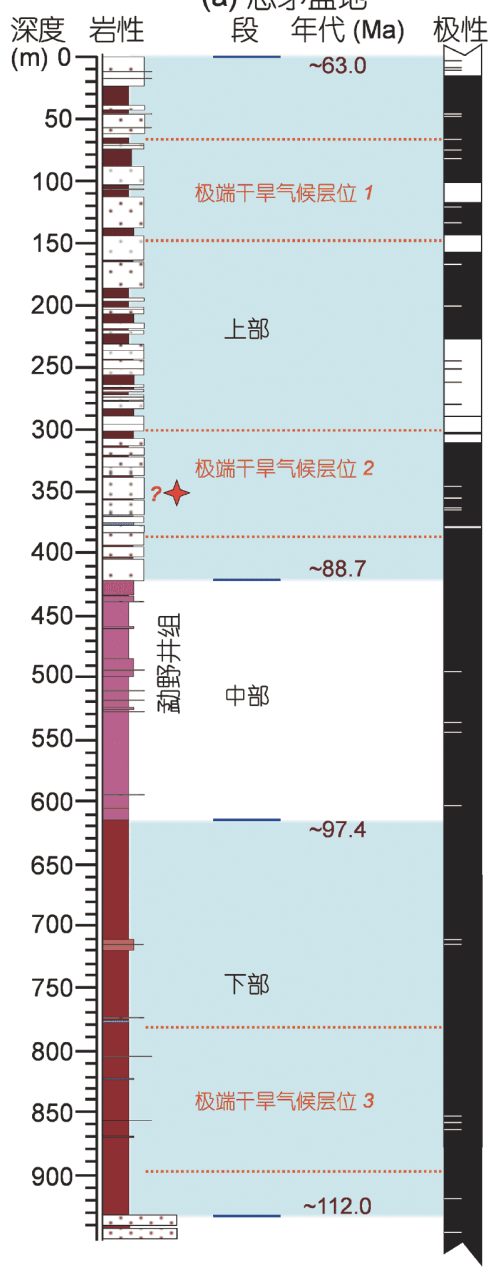

(b) 呵叻盆地

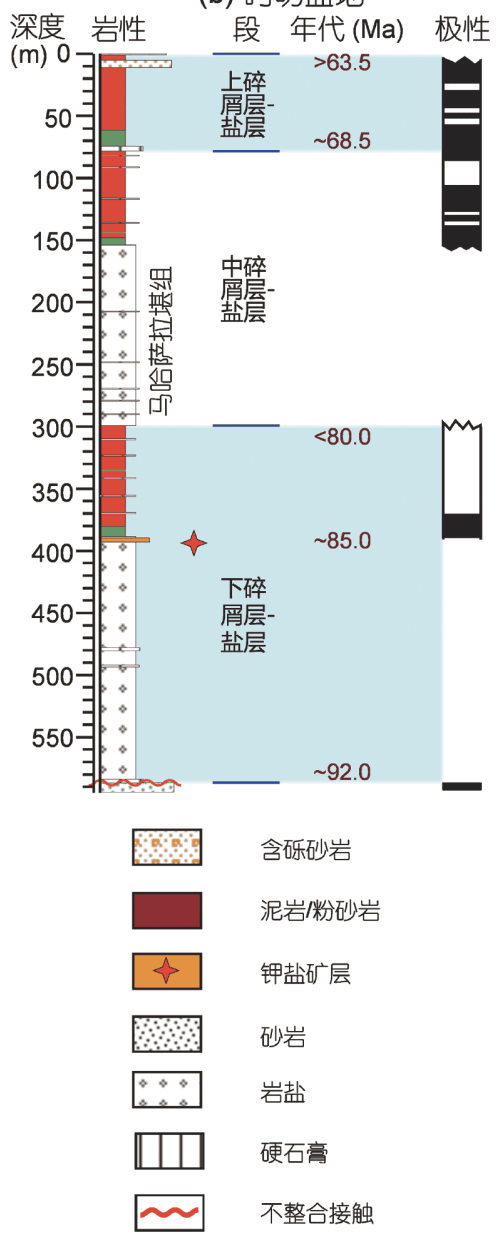

图 11 思茅盆地含钾盐地层预野井组(a)和呵叻盆地马哈萨拉堪组(b)的磁性地层年代学对比

(a)中极端干旱气候记录数据来自ITPCAS(2015); (b)修改自Zhang等(2018). 基于二者的磁性地层学结果, 马哈萨拉堪组地层可以与㐨野井组地 层中上部对比, 有别于以往认识(曲懿华, 1997)

1998), 均指示白严纪期间特提斯域东南端的呵叻-思 茅等地存在一个广大泛盆地的可能.

\subsection{2 全球和区域古气候记录}

干旱-极端干旱气候是钾盐形成的另一个关键因 素，而副热带高压被认为是全球海相钾盐成矿的最根 本条件(Warren, 2010; Liu等, 2018). 从全球尺度看, 海 陆分布特征对气候产生重要影响。超级大陆一潘基亚 大陆演化对全球气候变化产生了深远影响, 如超级季 风系统(如Fang等，2016). 侏罗纪至白严纪，随着潘基 亚大陆裂解和全球普遍高温(Huber等，1995; Kerr等， 1998; 胡修棉, 2005; Bice等, 2006; 王成善等, 2009)导
致海平面上升、大规模陆地区域被淹没(Miller等, 2005; Zhao, 2005; 王成善等, 2009), 为全球海相钾盐形 成创造了有利条件(Hay等, 2006; Warren, 2010; 刘成 林, 2013; 刘成林等, 2015).

思茅与呵叻盆地在侏罗纪-白严纪位于北半球副 热带高压带内, 其古气候环境受到全球板块和气候演 化的影响(刘成林等, 2015) (图13). 二叠纪末潘基亚大 陆形成触发了超级季风(Kutzbach和Gallimore，1989; Weissert和Mohr, 1996; Rais等, 2007; Fang等, 2016), 至晚侏罗世随着潘基亚大陆逐渐裂解，超级季风规模 缩减(Boucot等, 2009; Fang等, 2016), 东南亚古陆的大 部分进入干旱气候并在卡拉库姆、芫塘、思茅和呵叻 


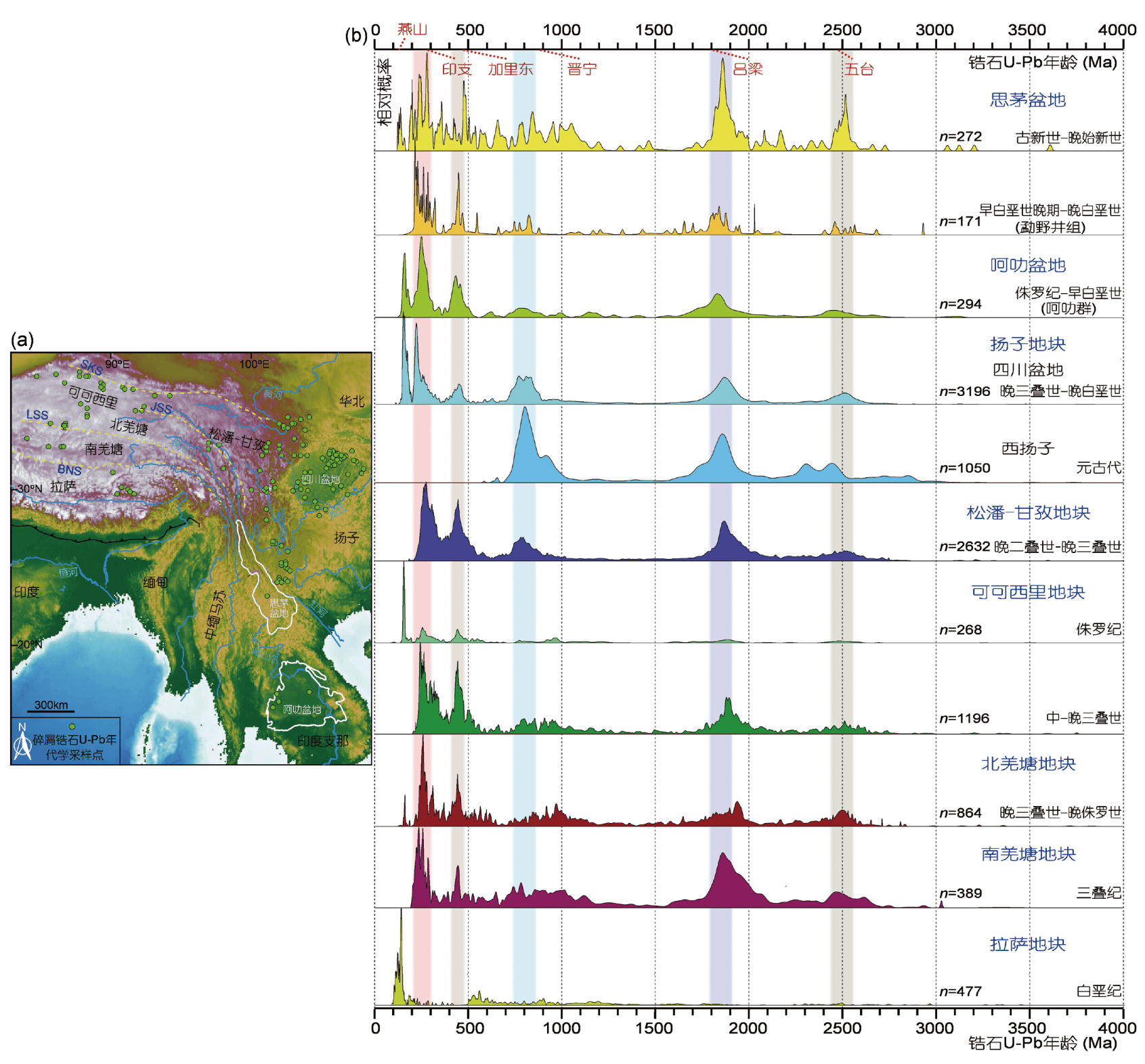

图 12 思茅与呵叻盆地及周边潜在物源区已有碎屑锆石U-Pb年代学采样点(a)和年龄分布图(b)

思茅盆地数据来自Wang等(2014)和Chen等(2017), 呵叻盆地数据来自Burrett等(2014), 扬子陆块数据来自Sun等(2009)、Zhao等(2010)、Wang 等(2012)、Luo等(2014)、Shao等(2016)和Li Y等(2016, 2018), 松潘-甘孜陆块数据来自Weislogel等(2006)、Enkelmann等(2007)、Ding等(2013) 和 Zhang等(2015), 可可西里陆块数据来自Ding等(2013), 北㒸塘陆块数据来自Ding等(2013)和Gehrels等(2011), 南羌塘数据来自Gehrels等 (2011), 拉萨陆块数据来自Leier等(2007). BNS, 班公-怒江缝合带; JSS, 金沙江缝合带; LSS, 龙木措-双湖缝合带; SKS, 南昆仑缝合带

盆地沉积巨厚红色碎屑蒸发岩. 白严纪随着潘基亚内 部大西洋扩张引发超级大陆的最终解体(图13a), 干旱 气候加强, 超级季风最终瓦解(Boucot等, 2009; Fang 等, 2016). 晚白严世, 行星风系在全球建立, 副热带高 压干旱气候影响了低纬大范围地区(图13b)，地球表生 环境形成大规模的蒸发岩, 如东南亚呵叻盆地 (刘成
林等, 2015; Liu等, 2018)和非洲西部下刚果盆地(Zhao 等, 2017)的晚白严世塞诺曼期-圣通期钾盐矿.

综上所述, 自中生代起, 思茅与呵叻盆地位于副热 带高压影响区域. 除受到超级季风影响的时期, 区域气 候整体干旱炎热, 尤其是晚三叠世、中-晚侏罗世和晚 白严世是具备成盐成钾的最有利气候时期. 


\section{4 钾盐矿形成机制}

思茅与呵叻盆地含钾盐地层详细的年代学研究表 明两个盆地的含钾地层年代并不完全重叠. 鉴于上述 古地理和古气候证据支持白严纪思茅-呵叻泛盆地的 存在(图13c，13d), 本文着重讨论思茅与呵叻盆地钾盐 矿形成关系.

(1) 呵叻与思茅盆地的钾盐矿分别属于马哈萨拉 堪组和预野井组地层中的原生矿床．其中老挝他曲地 区马哈萨拉堪组磁性地层年代为 $92 \sim 63 \mathrm{Ma}$ ，并约束其
钾盐矿层大致形成于 85Ma (Zhang等, 2018); 而预野 井组磁性地层年代学结果为 $>112$ 至 $63 \mathrm{Ma}$. 原先在 $\sim 110 \mathrm{Ma}$ 或 $65 \mathrm{Ma}$ 两个时段分别发育大量对钾盐形成 具有指示意义的泥砾岩和膏盐层(曲懿华，1997; 曲懿 华等, 1998) 以及地球化学指标也反映极端干旱气候特 征(ITPCAS，2015)，应是思茅盆地两个重要的潜在成 盐成钾期. 同时，考虑到晚白严世塞诺曼期-圣通期低 纬度古气候有利于钾盐形成(如呵叻盆地 ( Liu等, 2018)、下刚果盆地(Zhao等，2017))，两个盆地在白严 纪可能相互连通, 且呵叻盆地已有大型钾盐矿发现, 加
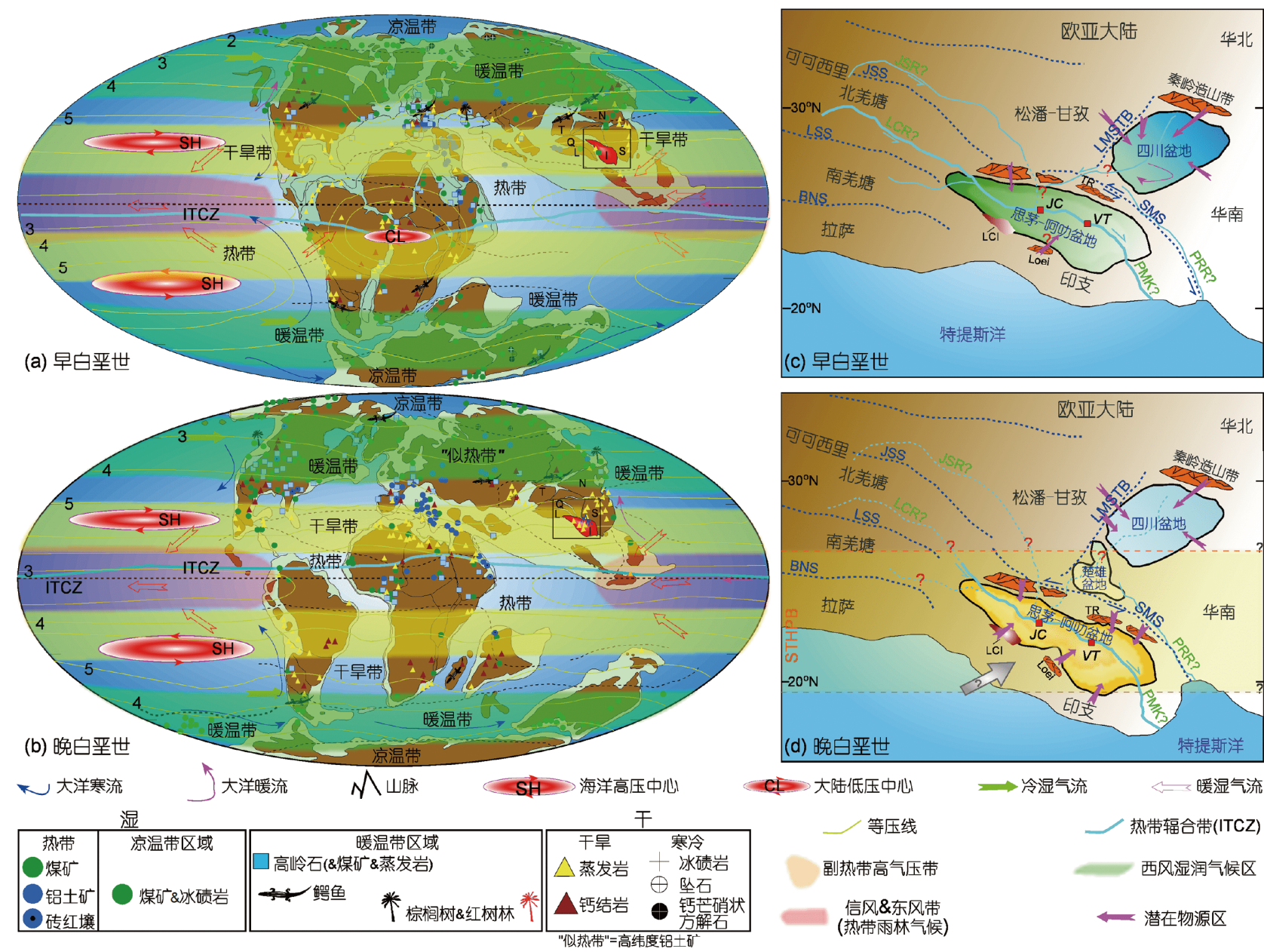

$\Longrightarrow$ 冷湿气流

1 暖湿气流

\section{图 13 早、晚白严世全球板块构造、气候格局及研究区古地理重建}

(a)和(b)为白严纪全球构造与古气候格局. 图中印支陆块使用红色标注. 全球板块和气候记录来自Boucot等(2009). 本文对塔里木(T)、并塘 $(\mathrm{Q}) 、$ 拉萨 $(\mathrm{L})$ 、华北 $(\mathrm{N})$ 、华南 $(\mathrm{S})$ 和印支 $(\mathrm{I})$ 陆块的古地理位置进行了重建(数据详见网络版附表 $A 5)$. 大气等压线是相对值(无单位). 工作模型 来自Fang等(2016). (c)和(d)为白严纪区域古地理重建, 显示了思茅与呵叻盆地及其与周边陆块的关系. 四川盆地和秦岭造山带古地理修改自 Carter和Bristow(2003). 副热带高气压带(STHPH)位置来自Hay和Floegel (2012). 灰色箭头指示了可能的海侵(Wang等, 2015). VT, 万象; JSR(?), 金沙江(?); LCI, 临沧花岗岩; LCR(?), 澜沧江(?); LMSTB, 龙门山逆冲带; PRR(?), 古红河(?); PMK(?), 古涺公河(?); SMS, 松马缝合带; TR, Truongson带 
上在预野井组中部也具有极端干旱气候事件记录 (ITPCAS, 2015)(图11a), 因此 85 Ma这个在呵叻盆地 发育大型钾盐矿的关键时段, 也可能是思茅盆地未来 钾盐勘探的另一个潜在重要时期.

(2) 预野井钾盐矿并不是预野井组地层中的原生 钾盐矿, 而是由深部钾盐受挤压塑流至预野井组地层 中. 最近，思茅盆地宝藏地区深钻工程在中侏罗统地 层钻遇厚 $70 \mathrm{~m}$ 含钾岩盐层(郑绵平等, 2014), 进一步支 持了这种可能. 即, 依据预野井钾盐矿“二层楼成矿模 式”(郑绵平等, 2014), 预野井组下伏中侏罗世也可能 是思茅盆地未来钾盐勘探的另一个潜在重要时期.

\section{5 结论}

详细的岩石磁学和岩相学分析表明江城剖面预野 井组记录了原始沉积磁组构, 赤铁矿为主要的载磁矿 物, 同时在地层上部有少量的磁铁矿. 系统热退磁分 离出 857 个特征剩磁方向, 通过褶皱检验、倒转检验 和DRM模型分析, 说明可能为原生地磁场方向. 剖面 中共识别出七个正极性和七个负极性带.

碎屑锆石 $\mathrm{U}-\mathrm{Pb}$ 年代学结果约束江城剖面 900 、 $600 、 300$ 和 $55 \mathrm{~m}$ 处的最大沉积年龄分别为 122.4 、 109.5、93.8和82.2Ma. 综合区域已有的其他年代学证 据，将预野井组磁极性序列与GPTS2012对比，获得该 套地层首个磁性地层年代学序列为 $>112$ 至 $63 \mathrm{Ma}$. 研究 表明思茅盆地含钾盐地层沉积要比呵叻盆地的早约 20Ma. 古地理和古气候综合集成分析为两个盆地钾盐 矿的形成及关系提供了新的认识.

致谢责任编委和两位若名评审专家提出宝贵意见和建 议, 吴福莉、任海东、脱世博、问宝华、方小辉、岳雅 慧和陈耀飞在野外样品采集和室内测试中给予帮助、指 导, 在此一并表示感谢.

\section{参考文献}

陈乐尧. 1980. 云南江城地区早白严世狍粉组合特征及地层意义. 见: 钾盐地质科学研究队, 编. 云南思茅地区钾盐地质论文集. 169202

邓军, 王庆飞, 陈福川, 李龚健, 杨立强, 王长明, 张静, 孙祥, 舒启海, 和文言, 高雪, 高亮, 刘学飞, 郑远川, 邱昆峰, 薛胜超, 徐佳豪. 2020. 再论三江特提斯复合成矿系统. 地学前缘, 27: 106-136
冯明刚, 吴军, 韩润生, 朱延浙, 严城民. 2005. 老挝万象地区含盐系 地层. 云南地质, 24: 407-413

韩元红, 马海州, 袁小龙, 张西营, 高东林. 2011. 兰坪-思茅盆地与呵 叻高原钾盐矿床综合对比. 盐湖研究, 19: 1-7

胡修棉. 2005. 白严纪中期异常地质事件与全球变化. 地学前缘, 12: 222-230

黄宝春, 李永安, 方晓思, 孙东江, 庞其清, 程政武, 李佩贤. 2005. 滇 中禄丰地区侏罗系磁性地层学研究. 地质通报, 24: 322-328

黄宝春, 周姚秀, 朱日祥. 2008. 从古地磁研究看中国大陆形成与演 化过程. 地学前缘, 15: 348-359

李代芸. 1987. 云南侏罗系、白严系的划分及其界线一一着重讨论 景星组、㐨野井组的时代. 云南地质, 6: 211-226

刘成林. 2013. 大陆裂谷盆地钾盐矿床特征与成矿作用. 地球学报, 34: $515-527$

刘成林, 赵艳军, 方小敏, 吕凤琳, 王立成, 颜茂都, 张华, 丁婷. 2015. 板块构造对海相钾盐矿床分布与成矿模式的控制. 地质学报, 89: 1893-1907

苗忠英, 郑绵平, 张雪飞, 张震, 高运志. 2019. 蒸发岩中硫同位素的 地球化学特征及其沉积学意义一—以思茅盆地MZK-3 井为例. 地质学报, 93: 1166-1179

牟传龙, 王剑, 余谦, 张立生. 1999. 兰坪中新生代沉积盆地演化. 矿 物岩石, 19: 30-36

秦占杰, 袁秦, 魏海成, 盛淑蓉, 山发寿. 2013. 老挝甘蒙省晚白严世 农波组孢粉组合及其对成盐环境的指示意义. 地球学报, 34 : 638-642

曲懿华. 1997. 兰坪-思茅盆地与泰国呵叻盆地含钾卤水同源性研究 ——兼论该区找钾有利层位和地区. 化工矿产地质, 19: 81-98

曲懿华, 袁品泉, 帅开业, 张瑛, 蔡克勤, 贾疏源, 陈朝德. 1998. 兰坪思茅盆地钾盐成矿规律及预测. 北京: 地质出版社. 1-120

宋之琛, 郑亚惠, 李曼英, 张一勇, 王伟铭, 王大宁, 赵传本, 周山富, 朱宗浩, 赵英娘. 1999. 中国狍粉化石. 北京: 科学出版社. 1-910 王成善, 曹珂, 黄永建. 2009. 沉积记录与白严纪地球表层系统变化. 地学前缘, 16: 1-14

夏文杰, 李秀华. 1983. 蒸发岩成因理论研究中的几个问题一一以云 南预野井钾盐石盐矿床为例. 矿物岩石, 3: 1-11

杨振宇, 孙知明, 马醒华, 尹济云, Otofuji Y. 2001. 红河断裂两侧早第 三纪古地磁研究及其地质意义. 地质学报, 75: 35-44

叶春辉, 蒋志文. 1981. 云南兰坪-思茅地区含盐地层的介形类化石. 古生物学报, 20: 153-162

袁秦, 秦占杰, 魏海成, 盛淑蓉, 山发寿. 2013. 云南江城预野井组钾 盐成矿时代及其古环境研究. 地球学报, 34: 631-637

云南省地质矿产局. 1976. 普洱幅地质图(比例尺1: 200,000)

云南省地质矿产局. 1986. 中华人民共和国地质矿产部地质专报. 北 京: 地质出版社

云南省地质矿产局. 1990. 云南省区域地质志. 北京: 地质出版社. 1728 
云南省地质矿产局. 1996. 云南省岩石地层. 武汉: 中国地质大学出 版社. 1-366

张嘉澎, 李官贤. 1980. 云南江城预野井钾盐矿床地质特征. 见: 钾盐 地质科学研究队, 编. 云南思茅地区钾盐地质论文集. 38-44 张西营, 程怀德, 谭红兵, 袁小龙, 李永寿, 苗卫良, 李廷伟, 马海州. 2015. 老挝中部沙湾拿吉盆地晚白严世钾盐蒸发岩: 非海相输入 的地球化学证据. 岩石学报, 31: 2783-2793

郑绵平, 齐文, 张永生. 2006. 中国钾盐地质资源现状与找钾方向初 步分析. 地质通报, 25: 1239-1246

郑绵平, 张震, 尹宏伟, 谭䈶虹, 于常青, 施林峰, 张雪飞, 杨尖絮, 焦 建, 武国朋. 2014. 云南江城预野井钾盐成矿新认识. 地球科学, 35: $11-24$

中国科学院青藏高原研究所(ITPCAS). 2015. 国家重点基础研究发 展计划项目 “中国陆块海相成钾规律及预测研究” (编号: 2011CB403000)第六课题“中国陆块漂移与干旱-极端干旱气候 事件及其对成钾控制”(编号: 2011CB403006)研究报告

钟晓勇, 袁秦, 秦占杰, 魏海成, 山发寿. 2012. 老挝甘蒙省晚白严世 农波组下段孢粉分析及成钾时代. 地球学报, 33: 323-330

朱创业, 夏文杰. 1997. 兰坪-思茅中生代盆地性质及构造演化. 成都 理工学院学报, 24: 23-30

Bice K L, Birgel D, Meyers P A, Dahl K A, Hinrichs K U, Norris R D. 2006. A multiple proxy and model study of Cretaceous upper ocean temperatures and atmospheric $\mathrm{CO}_{2}$ concentrations. Paleoceanography, 21: PA2002

Boucot A J, Chen X, Scotese C R, Fan J X. 2009. Phanerozoic Paleoclimate: An Atlas of Lithologic Indicators of Climate. Beijing: Science Press. 173

Burrett C, Khin Zaw C, Meffre S, Lai C K, Khositanont S, Chaodumrong P, Udchachon M, Ekins S, Halpin J. 2014. The configuration of Greater Gondwana-Evidence from LA ICPMS, $\mathrm{U}-\mathrm{Pb}$ geochronology of detrital zircons from the Palaeozoic and Mesozoic of Southeast Asia and China. Gondwana Res, 26: 31-51

Cai F, Ding L, Leary R J, Wang H, Xu Q, Zhang L, Yue Y. 2012 Tectonostratigraphy and provenance of an accretionary complex within the Yarlung-Zangpo suture zone, southern Tibet: Insights into subduction-accretion processes in the Neo-Tethys. Tectonophysics, 574-575: 181-192

Carter A, Bristow C S. 2003. Linking hinterland evolution and continental basin sedimentation by using detrital zircon thermochronology: A study of the Khorat Plateau Basin, eastern Thailand. Basin Res, 15: 271-285

Charusiri P, Imsamut S, Zhuang Z, Ampaiwan T, Xu X. 2006. Paleomagnetism of the earliest Cretaceous to early late Cretaceous sandstones, Khorat Group, Northeast Thailand: Implications for tectonic plate movement of the Indochina block. Gondwana Res, 9: $310-325$
Chen Y, Yan M, Fang X, Song C, Zhang W, Zan J, Zhang Z, Li B, Yang Y, Zhang D. 2017. Detrital zircon U-Pb geochronological and sedimentological study of the Simao Basin, Yunnan: Implications for the Early Cenozoic evolution of the Red River. Earth Planet Sci Lett, 476: 22-33

Deng C L, He H Y, Pan Y X, Zhu R X. 2013. Chronology of the terrestrial upper Cretaceous in the Songliao Basin, northeast Asia. Palaeogeogr Palaeoclimatol Palaeoecol, 385: 44-54

Dickinson W R, Gehrels G E. 2009. Use of U-Pb ages of detrital zircons to infer maximum depositional ages of strata: A test against a Colorado Plateau Mesozoic database. Earth Planet Sci Lett, 288: $115-125$

Ding L, Yang D, Cai F L, Pullen A, Kapp P, Gehrels G E, Zhang L Y, Zhang Q H, Lai Q Z, Yue Y H, Shi R D. 2013. Provenance analysis of the Mesozoic Hoh-Xil-Songpan-Ganzi turbidites in northern Tibet: Implications for the tectonic evolution of the eastern PaleoTethys Ocean. Tectonics, 32: 34-48

Dunlop D, Özdemir Ö. 1997. Rock Magnetism: Fundamentals and Frontiers. Cambridge: Cambridge University Press. 573

El Tabakh M, Utha-Aroon C, Schreiber B C. 1999. Sedimentology of the Cretaceous Maha Sarakham evaporites in the Khorat Plateau of northeastern Thailand. Sedimentary Geol, 123: 31-62

Enkelmann E, Weislogel A, Ratschbacher L, Eide E, Renno A, Wooden J. 2007. How was the Triassic Songpan-Ganzi basin filled? A provenance study. Tectonics, 26: TC4007

Fan P. 2000. Accreted terranes and mineral deposits of Indochina. J Asian Earth Sci, 18: 343-350

Fang X, Song C, Yan M, Zan J, Liu C, Sha J, Zhang W, Zeng Y, Wu S, Zhang D. 2016. Mesozoic litho- and magneto-stratigraphic evidence from the central Tibetan Plateau for megamonsoon evolution and potential evaporites. Gondwana Res, 37: 110-129

Fildani A, Cope T D, Graham S A, Wooden J L. 2003. Initiation of the Magallanes foreland basin: Timing of the southernmost Patagonian Andes orogeny revised by detrital zircon provenance analysis. Geology, 31: 1081-1084

Finlay C C, Maus S, Beggan C D, Bondar T N, Chambodut A, Chernova T A, Chulliat A, Golovkov V P, Hamilton B, Hamoudi M, Holme R, Hulot G, Kuang W, Langlais B, Lesur V, Lowes F J, Lühr H, Macmillan S, Mandea M, McLean S, Manoj C, Menvielle M, Michaelis I, Olsen N, Rauberg J, Rother M, Sabaka T J, Tangborn A, Tøffner-Clausen L, Thébault E, Thomson A W P, Wardinski I, Wei Z, Zvereva T I. 2010. International geomagnetic reference field: The eleventh generation. Geophys J Int, 183: 1216-1230

Fisher R. 1953. Dispersion on a sphere. Proc R Soc A-Math Phys Eng Sci, 217: 295-305

Fu X, Wang J, Tan F, Feng X, Wang D, He J. 2013. Gas hydrate 
formation and accumulation potential in the Qiangtang Basin, northern Tibet, China. Energy Convers Manage, 73: 186-194

Gao L, Yang Z, Tong Y, Wang H, An C. 2015. New paleomagnetic studies of Cretaceous and Miocene rocks from Jinggu, western Yunnan, China: Evidence for internal deformation of the LanpingSimao Terrane. J GeoDyn, 89: 39-59

Gardner L S, Hayworth H F, Changmai P N. 1967. Salt Resource of Thailand. Report of Investigation No. 11. Bangkok: Department of Mineral Resources

Gehrels G, Kapp P, Decelles P, Pullen A, Blakey R, Weislogel A, Ding L, Guynn J, Martin A, McQuarrie N, Yin A. 2011. Detrital zircon geochronology of pre-Tertiary strata in the Tibetan-Himalayan orogen. Tectonics, 30: TC5016

Gehrels G, Valencia V, Pullen A. 2006. Detrital zircon geochronology by laserablation multicollector ICPMS at the Arizona Laser-Chron Center. In: Olszewski T, Huff W. eds. Geochronology: Emerging Opportunities. Pennsylvania: Paleontological Society Short Course. $1-10$

Gradstein F M, Ogg J G, Schmitz M D, Ogg G M. 2012. The Geological Time Scale 2012. Waltham: Elsevier. 1144

Hansen B T, Wemmer K, Eckhardt M, Putthapiban P, Assavapatchara S. 2016. Isotope Dating of the Potash and Rock Salt Deposit at Bamnet Narong, NE-Thailand. OJG, 06: 875-894

Hansen B T, Wemmer K, Pawlig S, Klaus J, Assavapatchara S, Nontaso M, Chairangsee C, Putthapiban P. 2002. Isotopic evidence for a Late Cretaceous age of the potash and rock salt deposit at Bamnet Narong, NE Thailand. In: Mantajit N, ed. The Symposium on Geology of Thailand. Bangkok: Department of Mineral Resources

Harris R W. 1977. Paleontology of the Phu Horm-1 Well. In: Harris R W. ed. Open File Report of ESSO. Bangkok: Department of Mineral Resources

Hay W W, Floegel S. 2012. New thoughts about the Cretaceous climate and oceans. Earth-Sci Rev, 115: 262-272

Hay W W, Migdisov A, Balukhovsky A N, Wold C N, Flögel S, Söding E. 2006. Evaporites and the salinity of the ocean during the Phanerozoic: Implications for climate, ocean circulation and life. Palaeogeogr Palaeoclimatol Palaeoecol, 240: 3-46

He H Y, Deng C L, Wang P J, Pan Y X, Zhu R X. 2012. Toward age determination of the termination of the Cretaceous Normal Superchron. Geochem Geophys Geosyst, 13: Q02002

Hite R J, Japakasetr T. 1979. Potash deposits of the Khorat Plateau, Thailand and Laos. Economic Geol, 74: 448-458

Horton B K, Anderson V J, Caballero V, Saylor J E, Nie J, Parra M, Mora A. 2015. Application of detrital zircon U-Pb geochronology to surface and subsurface correlations of provenance, paleodrainage, and tectonics of the Middle Magdalena Valley Basin of Colombia.
Geosphere, 11: 1790-1811

Hou Z Q, Xie Y L, Xu W Y, Li Y Q, Zhu X K, Zaw K, Beaudoin G, Rui Z Y, Huang W, Ciren L. 2007. Yulong deposit, eastern Tibet: A high-sulfidation $\mathrm{Cu}-\mathrm{Au}$ porphyry copper deposit in the eastern IndoAsian collision zone. Int Geol Rev, 49: 235-258

Huber B T, Hodell D A, Hamilton C P. 1995. Middle-Late Cretaceous climate of the southern high latitudes: Stable isotopic evidence for minimal equator-to-pole thermal gradients. Geological Soc Am Bull, 107: 1164-1191

Jackson M. 1990. Diagenetic sources of stable remanence in remagnetized Paleozoic cratonic carbonates: A rock magnetic study. J Geophys Res, 95: 2753-2761

Jiang Z, Liu Q, Dekkers M J, Tauxe L, Qin H, Barrón V, Torrent J. 2015. Acquisition of chemical remanent magnetization during experimental ferrihydrite-hematite conversion in Earth-like magnetic field-Implications for paleomagnetic studies of red beds. Earth Planet Sci Lett, 428: 1-10

Kent D V, Miller J D. 1987. Redbeds and thermoviscous magnetization theory. Geophys Res Lett, 14: 327-330

Kerr A C, Tarney J, Nivia A, Marriner G F, Saunders A D. 1998. The internal structure of oceanic plateaus: Inferences from obducted Cretaceous terranes in western Colombia and the Caribbean. Tectonophysics, 292: 173-188

Kirschvink J L. 1980. The least-squares line and plane and the analysis of palaeomagnetic data. Geophys J Int, 62: 699-718

Kondo K, Mu C, Yamamoto T, Zaman H, Miura D, Yokoyama M, Ahn H S, Otofuji Y. 2012. Oroclinal origin of the Simao arc in the ShanThai block inferred from the Cretaceous palaeomagnetic data. Geophys J Int, 190: 201-216

Kutzbach J E, Gallimore R G. 1989. Pangaean climates: Megamonsoons of the megacontinent. J Geophys Res, 94: 3341-3357

Leier A L, Kapp P, Gehrels G E, DeCelles P G. 2007. Detrital zircon geochronology of Carboniferous? Cretaceous strata in the Lhasa terrane, Southern Tibet. Basin Res, 19: 361-378

Li M, Yan M, Fang X, Zhang Z, Wang Z, Sun S, Li J, Liu X. 2018. Origins of the Mid-Cretaceous evaporite deposits of the Sakhon Nakhon Basin in Laos: Evidence from the stable isotopes of halite. J Geo Chem Exploration, 184: 209-222

Li M, Yan M, Wang Z, Liu X, Fang X, Li J. 2015. The origins of the Mengye potash deposit in the Lanping-Simao Basin, Yunnan Province, Western China. Ore Geol Rev, 69: 174-186

Li P, Rui G, Junwen C, Ye G. 2004. Paleomagnetic analysis of eastern Tibet: Implications for the collisional and amalgamation history of the Three Rivers Region, SW China. J Asian Earth Sci, 24: 291-310

Li S, Yang Z, Deng C, He H, Qin H, Sun L, Yuan J, van Hinsbergen D J J, Krijgsman W, Dekkers M J, Pan Y, Zhu R. 2017. Clockwise 
rotations recorded in redbeds from the Jinggu Basin of northwestern Indochina. Geological Soc Am Bull, 129: 1100-1122

Li Y, He D, Li D, Wen Z, Mei Q, Li C, Sun Y. 2016. Detrital zircon U$\mathrm{Pb}$ geochronology and provenance of Lower Cretaceous sediments: Constraints for the northwestern Sichuan pro-foreland basin. Palaeogeogr Palaeoclimatol Palaeoecol, 453: 52-72

Li Y, He D, Li D, Lu R, Fan C, Sun Y, Huang H. 2018. Sedimentary provenance constraints on the Jurassic to Cretaceous paleogeography of Sichuan Basin, SW China. Gondwana Res, 60: 15-33

Liu C, Wang L, Yan M, Zhao Y, Cao Y, Fang X, Shen L, Wu C, Lv F, Ding T. 2018. The Mesozoic-Cenozoic tectonic settings, paleogeography and evaporitic sedimentation of Tethyan blocks within China: Implications for potash formation. Ore Geol Rev, 102: 406425

Ludwig K R. 2003. User's Manual for Isoplot 3.00. A Geochronological Toolkit for Microsoft Excel. California: Berkeley Geochronology Center

Luo L, Qi J F, Zhang M Z, Wang K, Han Y Z. 2014. Detrital zircon U$\mathrm{Pb}$ ages of Late Triassic-Late Jurassic deposits in the western and northern Sichuan Basin margin: constraints on the foreland basin provenance and tectonic implications. Int J Earth Sci-Geol Rundsch, 103: $1553-1568$

Maranate S. 1982. Paleomagnetism of the Khorat Group in Northeast Thailand. Master Dissertation. Wellington: Victoria University of Wellington

Maranate S, Vella P. 1986. Paleomagnetism of the Khorat Group Mesozoic, northeast Thailand. J Southeast Asian Earth Sci, 1: 23-31

McFadden P L. 1990. A new fold test for palaeomagnetic studies Geophys J Int, 103: 163-169

McFadden P L, McElhinny M W. 1990. Classification of the reversal test in palaeomagnetism. Geophys J Int, 103: 725-729

Metcalfe I. 2011. Tectonic framework and Phanerozoic evolution of Sundaland. Gondwana Res, 19: 3-21

Metcalfe I. 2013. Gondwana dispersion and Asian accretion: Tectonic and palaeogeographic evolution of eastern Tethys. J Asian Earth Sci, 66: $1-33$

Miller K G, Kominz M A, Browning J V, Wright J D, Mountain G S, Katz M E, Sugarman P J, Cramer B S, Christie-Blick N, Pekar S F. 2005. The Phanerozoic record of global sea-level change. Science, 310: $1293-1298$

Nelson D R. 2001. An assessment of the determination of depositional ages for precambrian clastic sedimentary rocks by $\mathrm{U}-\mathrm{Pb}$ dating of detrital zircons. Sedimentary Geol, 141-142: 37-60

Parés J M, van der Pluijm B A. 2002. Evaluating magnetic lineations (AMS) in deformed rocks. Tectonophysics, 350: 283-298

Parés J M, van der Pluijm B A, Dinarès-Turell J. 1999. Evolution of magnetic fabrics during incipient deformation of mudrocks (Pyrenees, northern Spain). Tectonophysics, 307: 1-14

Pisutha-Arnond V, Chiba H, Yumuang S. 1986. A preliminary sulphur and oxygen isotope study of the Maha Sarakham evaporitic anhydrite from Bamnet Narong Area of NE Thailand. Geol Soc Malays Bull, 19: 209-222

Qin Z, Li Q, Zhang X, Fan Q, Wang J, Du Y, Ma Y, Wei H, Yuan Q, Shan F. 2020. Origin and recharge model of the Late Cretaceous evaporites in the Khorat Plateau. Ore Geol Rev, 116: 103226

Racey A, Goodall J G S. 2009. Palynology and stratigraphy of the Mesozoic Khorat Group red bed sequences from Thailand. Geological Soc London Spec Publ, 315: 69-83

Rais P, Louis-Schmid B, Bernasconi S M, Weissert H. 2007. Palaeoceanographic and palaeoclimatic reorganization around the Middle-Late Jurassic transition. Palaeogeogr Palaeoclimatol Palaeoecol, 251: 527-546

Roberts A P, Cui Y, Verosub K L. 1995. Wasp-waisted hysteresis loops: Mineral magnetic characteristics and discrimination of components in mixed magnetic systems. J Geophys Res, 100: 17909-17924

Sengör A M C, Natal'in B A. 1996. Paleotectonics of Asia: Fragments of a synthesis. In: Yin A, Harrison M, eds. The Tectonic Evolution of Asia. London: Cambridge University Press. 443-486

Sharman G R, Malkowski M A. 2020. Needles in a haystack: Detrital zircon $\mathrm{U}-\mathrm{Pb}$ ages and the maximum depositional age of modern global sediment. Earth-Sci Rev, 203: 103109

Shao T, Cheng N, Song M. 2016. Provenance and tectonic-paleogeographic evolution: Constraints from detrital zircon $\mathrm{U}-\mathrm{Pb}$ ages of Late Triassic-Early Jurassic deposits in the northern Sichuan basin, central China. J Asian Earth Sci, 127: 12-31

Shen M, Zan J, Yan M, Zhang W, Fang X, Zhang D, Zhang T. 2020. Comparative rock magnetic study of Eocene volcanogenic and sedimentary rocks from Yunnan, southeastern Tibetan Plateau, and its geological implications. J Geophys Res Solid Earth, 125: e17946

Singsoupho S, Bhongsuwan T, Elming S Å. 2014. Tectonic evaluation of the Indochina Block during Jurassic-Cretaceous from palaeomagnetic results of Mesozoic redbeds in central and southern Lao PDR. J Asian Earth Sci, 92: 18-35

Sone M, Metcalfe I. 2008. Parallel Tethyan sutures in mainland Southeast Asia: New insights for Palaeo-Tethys closure and implications for the Indosinian orogeny. Comptes Rendus Geosci, 340: $166-179$

Sun J, Xiao W, Windley B F, Ji W, Fu B, Wang J, Jin C. 2016. Provenance change of sediment input in the northeastern foreland of Pamir related to collision of the Indian Plate with the KohistanLadakh arc at around $47 \mathrm{Ma}$. Tectonics, 35: 315-338 
Sun W H, Zhou M F, Gao J F, Yang Y H, Zhao X F, Zhao J H. 2009. Detrital zircon U-Pb geochronological and Lu-Hf isotopic constraints on the Precambrian magmatic and crustal evolution of the western Yangtze Block, SW China. Precambrian Res, 172: 99-126

Suwanich P. 1986. Potash and rock salt in Thailand. In: Nonmetallic Minerals Bulletin No. 2 Economic Geology Division. Bangkok: Department of Mineral Resources

Tarling D H, Hrouda F. 1993. The Magnetic Anisotropy of Rocks. London: Chapman and Hall. 217

Tauxe L. 1998. Paleomagnetic Principles and Practice. Dordrecht: Kluwer Academic Publishers. 299

Tauxe L, Mullender T A T, Pick T. 1996. Potbellies, wasp-waists, and superparamagnetism in magnetic hysteresis. J Geophys Res, 101: $571-583$

Tong Y B, Yang Z, Zheng L D, Xu Y L, Wang H, Gao L, Hu X Z. 2013 Internal crustal deformation in the northern part of Shan-Thai Block: New evidence from paleomagnetic results of Cretaceous and Paleogene redbeds. Tectonophysics, 608: 1138-1158

Wang B Q, Zhou M F, Li J W, Yan D P. 2011. Late Triassic porphyritic intrusions and associated volcanic rocks from the Shangri-La region, Yidun terrane, Eastern Tibetan Plateau: Adakitic magmatism and porphyry copper mineralization. Lithos, 127: 24-38

Wang E C, Burchfiel B C, Royden L H, Chen L Z, Chen J S, Li W X, Chen Z L. 1998. Late Cenozoic Xianshuihe-Xiaojiang, Red River, and Dali Fault Systems of Southwestern Sichuan and Central Yunnan, China. Geol Soc Am Special Paper, 327: 1-108

Wang L, Liu C, Fei M, Shen L, Zhang H, Zhao Y. 2015. First shrimp U$\mathrm{Pb}$ zircon ages of the potash-bearing Mengyejing Formation, Simao Basin, southwestern Yunnan, China. Cretac Res, 52: 238-250

Wang L, Liu C, Gao X, Zhang H. 2014. Provenance and paleogeography of the Late Cretaceous Mengyejing Formation, Simao Basin, southeastern Tibetan Plateau: Whole-rock geochemistry, U-Pb geochronology, and Hf isotopic constraints. Sedimentary Geol, 304: 44-58

Wang L J, Yu J H, Griffin W L, O’Reilly S Y. 2012. Early crustal evolution in the western Yangtze Block: Evidence from $\mathrm{U}-\mathrm{Pb}$ and Lu-Hf isotopes on detrital zircons from sedimentary rocks. Precambrian Res, 222-223: 368-385

Warren J K. 2010. Evaporites through time: Tectonic, climatic and eustatic controls in marine and nonmarine deposits. Earth-Sci Rev, 98: $217-268$

Watson G S, Enkin R J. 1993. The fold test in paleomagnetism as a parameter estimation problem. Geophys Res Lett, 20: 2135-2137

Weislogel A L, Graham S A, Chang E Z, Wooden J L, Gehrels G E, Yang H. 2006. Detrital zircon provenance of the Late Triassic Songpan-Ganzi complex: Sedimentary record of collision of the North and South China blocks. Geology, 34: 97-100

Weissert H, Mohr H. 1996. Late Jurassic climate and its impact on carbon cycling. Palaeogeogr Palaeoclimatol Palaeoecol, 122: 27-43

Yan M, Zhang D, Fang X, Ren H, Zhang W, Zan J, Song C, Zhang T. 2016. Paleomagnetic data bearing on the Mesozoic deformation of the Qiangtang Block: Implications for the evolution of the Paleoand Meso-Tethys. Gondwana Res, 39: 292-316

Yang Z, Besse J. 2001. New Mesozoic apparent polar wander path for south China: Tectonic consequences. J Geophys Res, 106: 84938520

Zhang D, Yan M, Fang X, Yang Y, Zhang T, Zan J, Zhang W, Liu C, Yang Q. 2018. Magnetostratigraphic study of the potash-bearing strata from drilling core ZK2893 in the Sakhon Nakhon Basin, eastern Khorat Plateau. Palaeogeogr Palaeoclimatol Palaeoecol, 489: 40-51

Zhang W, Yan M, Fang X, Zhang D, Zhang T, Zan J, Song C. 2019. High-resolution paleomagnetic constraint on the oldest hominoidfossil-bearing sequence in the Xiaolongtan Basin, southeast margin of the Tibetan Plateau and its geologic implications. Glob Planet Change, 182: 103001

Zhang Y X, Zeng L, Li Z W, Wang C S, Zhang K J, Yang W G, Guo T L. 2015. Late Permian-Triassic siliciclastic provenance, palaeogeography, and crustal growth of the Songpan terrane, eastern Tibetan Plateau: evidence from $\mathrm{U}-\mathrm{Pb}$ ages, trace elements, and $\mathrm{Hf}$ isotopes of detrital zircons. Int Geol Rev, 57: 159-181

Zhao X, Wang Z, Liu C, Li C, Jiao P, Zhao Y, Zhang F. 2017. Characteristics and geological significance of Re-Os isotopic system of evaporites in Mboukoumassi Deposit, the Republic of Congo. J African Earth Sci, 138: 14-21

Zhao X F, Zhou M F, Li J W, Sun M, Gao J F, Sun W H, Yang J H. 2010. Late Paleoproterozoic to early Mesoproterozoic Dongchuan Group in Yunnan, SW China: Implications for tectonic evolution of the Yangtze Block. Precambrian Res, 182: 57-69

Zhao X X. 2005. The Earth's magnetic field and global geologic phenomena in Mid-Cretaceous. Earth Sci Front, 12: 199-216

Zijderveld J D A. 1967. A.C. Demagnetization of rocks: Analysis of results. In: Collinson D W, Creer K M, Runcorn S K. eds. Methods in Palaeomagnetism. Amsterdam: Elsevier. 254-286

(责任编委: 朱茂炎) 